Article

\title{
Synchronous Sampling-Based Direct Current Estimation Method for Self-Sensing Active Magnetic Bearings
}

\author{
Xiongxin $\mathrm{Hu}{ }^{1,2}$, Fang $X \mathrm{u}^{1,2}$, Ronghui Wang ${ }^{1,2}$ and Dapeng Tan $1,2,3, * \mathbb{C}$ \\ 1 College of Mechanical Engineering, Zhejiang University of Technology, Hangzhou 310014, China; \\ huxx007@zjut.edu.cn (X.H.); fangx@zjut.edu.cn (F.X.); 2111802073@zjut.edu.cn (R.W.) \\ 2 Key Laboratory of Special Purpose Equipment and Advanced Processing Technology, Ministry of Education \\ and Zhejiang Province, Zhejiang University of Technology, Hangzhou 310014, China \\ 3 Collaborative Innovation Center of High-end Laser Manufacturing Equipment (National “2011 Plan”), \\ Zhejiang University of Technology, Hangzhou 310014, China \\ * Correspondence: tandapeng@zjut.edu.cn
}

Received: 28 April 2020; Accepted: 18 June 2020; Published: 20 June 2020

\begin{abstract}
Active magnetic bearings (AMBs) commonly use pulse-width modulation to reduce analogous hardware and manufacturing costs, but they experience sensing process, sensing accuracy and stability problems. To address these issues, a synchronous sampling-based direct current estimation (SS-DCE) method is proposed herein with a bistate switching power amplifier. First—considering the reluctance evolution mechanism of AMBs-a coupling relation mathematical model between rotor displacement and voltage/current is presented to acquire the rotor position from the working coil current alone. Then-assuming that the switching current was an approximately triangular signal — DCE for the rotor position was established based on the estimation inductance of the charging/discharging phase. Finally-to decrease the phase shift caused by the self-sensing filters and position estimation algorithms - the SS-DCE method was introduced to conduct precise position detection for rotors with high velocities. The simulation and experimental results indicated that the proposed method could improve the sensing accuracy and stability. Compared to other AMB position estimation methods, the simple linearity of the SS-DCE method was greatly improved and could be controlled below $4 \%$. Evaluation using frequency response analysis showed that the SS-DCE method had excellent dynamic accuracy and could perform at a higher phase margin, especially for the uprising/landing transient state. Moreover, there was a phase margin of $158^{\circ}$ at the natural frequency of $19.26 \mathrm{HZ}$, and the peak sensitivity in the 50-250 $\mu \mathrm{m}$ range reached $10.7 \mathrm{~dB}$.
\end{abstract}

Keywords: self-sensing; active magnetic bearings; least square method; direct current estimator; synchronous sampling

\section{Introduction}

For the rotating machinery of pumps, generators, turbomachines or machine tools, the rotors are generally supported by hydraulic bearings, composite ceramic bearings or magnetic bearings. Due to their high-speed rotation, high efficiency and low maintenance demand, active magnetic bearings (AMBs) have been applied in a series of modern industrial high-speed motor systems to replace conventional bearings. However, their geometric size, manufacturing cost and work reliability are disadvantageous as they comprise numerous components, such as wires, electromagnetic actuators, sensors and controllers. If some of these components are eliminated or integrated, the cost and size can be reduced, and the system reliability can be improved. The first self-sensing method proposed by Vischer [1] is based on the Luenberger model, but its estimation results are sensitive to 
systematic parameter changes. However, Cannon et al. [2] and Karkoub et al. [3] found that stable control is easy to achieve in flexible structures with co-located sensors and actuators. For example, a generic AMB-supported rotor, peripheral hardware and free-free rotor mode [4] are shown in Figure 1. This AMB structure is non-collocated because the position sensor is set beside the actuator (electromagnet); the phase difference between the position sensor and the actuator can be potentially dangerous if the rotor is running in a high-order mode. Then, the co-located solution, called self-sensing method, is developed, and the phase difference will be eliminated because the position sensor and the actuator will combine.

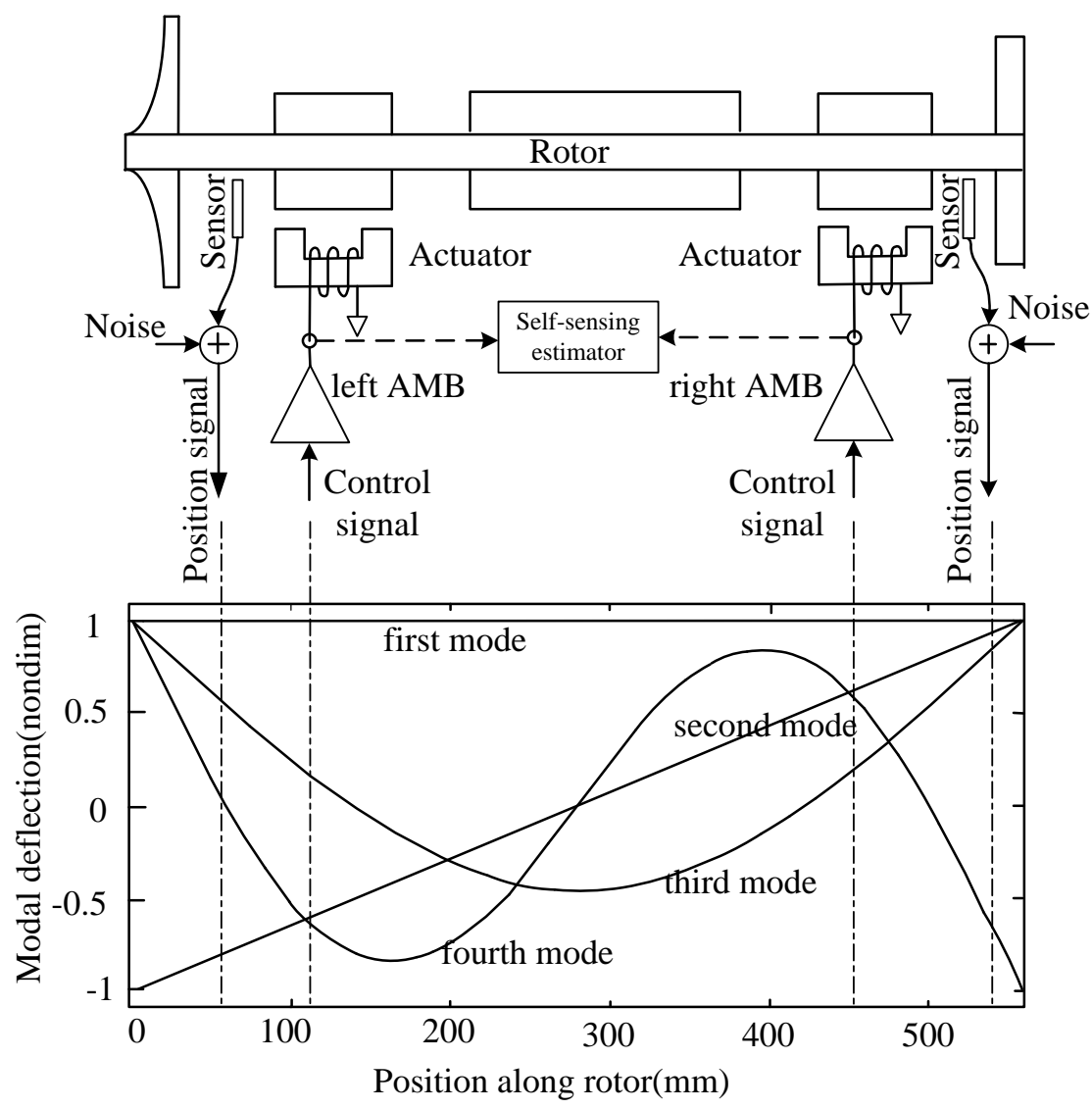

Figure 1. Example of a generic active magnetic bearing (AMB) system and free-free rotor mode.

Self-sensing methods can be divided into two main categories: state observer-based and parameter estimator-based methods. Vischer [5] and Mizuno [6] presented the rotor position as a system state, but the system robustness based on the observer was lacking in comparison to that based on the sensor. In 1998, Morse [7] first proposed that the design scheme of self-sensing bearings lacks robustness to the bearing model's uncertainty; hence, several parameter estimators were developed. A high-frequency small dither signal is injected into the coil of AMBs because Maslen [8] showed that the linear period signal can increase robustness. The inductance change was detected and the rotor position was estimated by Park et al. [9], Ghule et al. [10], Bugsch et al. [11] and Tan et al. [12]. However, this approach is limited by the bandwidth of the power amplifier (PA) and the signal-to-noise ratio. Another solution based on the ripples of a pulse-width modulation (PWM) PA introduced by Okada [13] and Noh [14] showed that the PWM ripple components are demodulated to estimate the rotor position, because the working current and voltage of AMBs are related to the inductance of the bearing coil. To overcome the disadvantage of the duty cycle of the PWM PA current not being fixed and affecting the detection accuracy, Mizuno [15] used a hysteresis amplifier to drive the magnetic bearing and converted the rotor displacement to the switching frequency of the hysteresis amplifier. Furthermore, 
Schammass [16] suggested that digital filtering amplitude demodulation (DFAD) is better than Noh's analog approach.

The analog solution of Schammass's approach is shown in Figure 2, while its digital solution is shown in Figure 3. Both solutions inherently involve the band-pass filter (BPF), rectifier or absolution algorithm and low-pass filter (LPF) to isolate the fundamental ripples of the coil current and voltage. Lu et al. [17], Zhang et al. [18,19], Pan et al. [20] and Tan et al. [21,22] investigated the digital model of amplitude demodulation. Similarly, Yu et al. [23] and Li et al [24,25] improved the estimation accuracy using an accurate analytical model in the frequency domain. Moreover, the displacement estimation module of the amplitude demodulation method has been constructed, including BPF, LPF and envelope detection module. Compared to the analog filtering amplitude demodulation (AFAD), DFAD increases the ADC (analog-to-digital converter) and replaces the analog filters with digital filters. Therefore, the outputs of the two estimators roughly have the same gain and phase response. The advantage of the amplitude demodulation estimation of both approaches is that it can conduct relatively mature electronic technology and involve communication demodulation method.

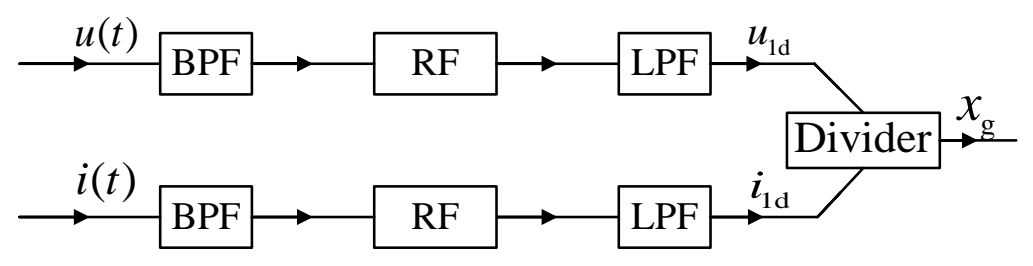

Figure 2. Diagram of the AFAD approach.

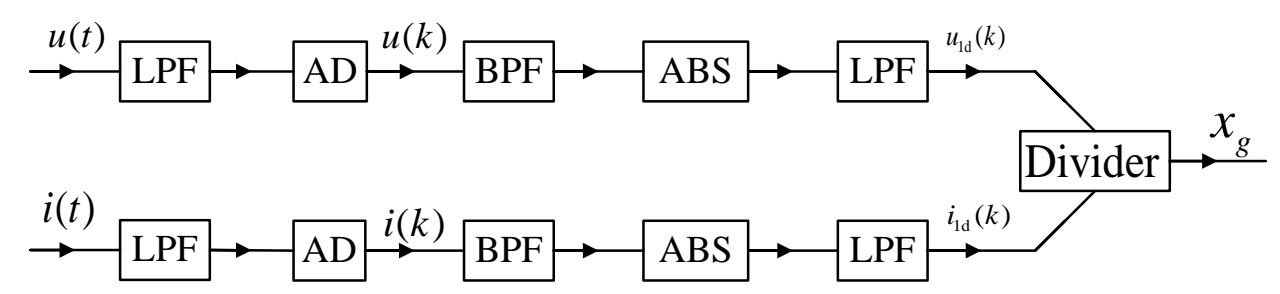

Figure 3. Diagram of the digital filtering amplitude demodulation (DFAD) approach.

In general, the extra phase shift is inevitably introduced in the demodulator self-sensing process, comprising the signal conditioning the electronic circuits, the filters extracting the fundamental ripple and the position estimation algorithm operation. Another issue is the nonlinear effect of the change of the duty cycle, by which the estimation accuracy, stability and robustness will inevitably decrease.

Another position estimation approach is gradient demodulation, which uses the coil current gradient signal. Li et al. [26] presented a self-sensing model based on the current change rate and Haarnoja et al. [27], Tian et al. [28] and Zhang et al. [29,30] reported that the rotor position can be estimated by the current slope due to the switching amplifier. This approach is obviously advantageous as no filters are employed in the self-sensing process and the nonlinear compensation of the duty cycle change effect is eliminated. Figure 4 shows the diagram of the gradient demodulation estimator. After the signal passes the anti-alias LPF, the demodulation method extracts the position information from the current's rate of change $(\mathrm{di} / \mathrm{dt})$ or the gradient. In the figure, $K_{\mathrm{N}}$ is the product of the coil length and the self-inductance, $V$ is the voltage, $i$ is the current and $\mathrm{t}$ is the time.

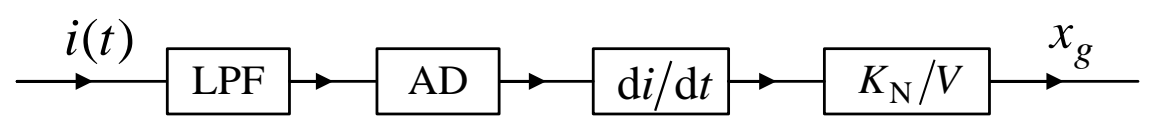

Figure 4. Diagram of the current gradient demodulation approach.

Since the current sampling method and technique are limited by the nonlinear magnetic effect and the eddy current in the PA transients, several challenges exist in the precise measurement of the current 
slope. Hence, Glück et al. [31] and Rizzello et al. [32,33] proposed a rotor position calculated by the estimation inductance based on the least squares identification model with the coil current. Evidently, a large phase shift is introduced by a more complex algorithm of position estimation and the ADC with higher speed and greater precision is adopted in the self-sensing process [34]. The extra phase shift introduced by the complex estimation algorithm reported by Nevaranta et al. [35], Sun et al. [36], Yang et al. [37] and Ge et al. [38] or the advanced filters proposed by Sun et al. [39] and Matsuda et al. [40] will affect the stability and robustness of AMBs. Consequently, developing a technical solution scheme with an adequate phase margin for the long-term operation of self-sensing AMBs is necessary.

As the switching frequency is generally high, updating the rotor position at each switching cycle is difficult. Therefore, Ranft et al. [41], Van Schoor et al. [42] and Yu et al. [43] and Li et al. [44] suggested the reduction of the switching frequency or updating of the position every several cycles. Apparently, for self-sensing AMBs to adapt to high-speed rotary machines is challenging.

If no flux cross-coupling is present between adjacent poles of the eight-pole heteropolar radial $\mathrm{AMB}$, we can set up a principle model of a single-degree-of-freedom (DOF) AMB, as shown in Figure 5 . Based on the model, the self-sensing solution employs an estimator that uses the coil current and voltage to calculate the gap between the rotor and stator [45]. The self-sensing estimator tends to utilize filters to extract the target signal, and its digital implementation must use the AD convector. Finite impulse response (FIR) filters or electronic filters are adopted in the self-sensing process. Since the external phase shift is introduced by the filters and complex estimation algorithms, the system stability margin will be limited. The symmetrical design of the demodulation circuit is the key section that concurrently takes charge of the fundamental current and voltage extraction process. Consequently, PWM switch amplifiers based on self-sensing schemes experience sensing process, sensing accuracy and work stability problems.
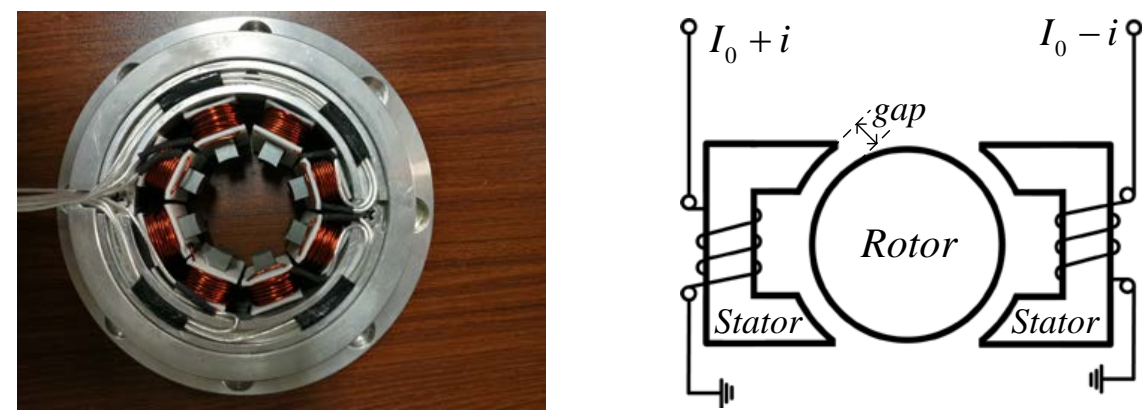

Figure 5. Eight-pole heteropolar radial stator (left) and single-degree-of-freedom (DOF) model of AMB (right).

To address this issue, Schammass [16] proposed a normal ADC applied with the analog solution because the synchronous demodulator's output is the fundamental ripple of the voltage and current. It is an inevitable consequence of the large phase shift introduced by the BPF and LPF in Niemann's work [46]. Therefore, the temperature sensitivity and phase shift can be improved in the digital solution; another advantage of this solution is that changing the mathematical algorithm is easy $[47,48]$. The stability margin of the system will be limited since an extra phase shift is introduced by the FIR filters and complex estimation algorithms [11]. In addition, the symmetrical design of the demodulation plays a key role in the position estimator [49].

To address the above problems, this study proposes a position estimation method that can not only extract the rotor position from the current gradient information, but also reduce the overhead time of the estimation algorithm's operation. A direct current estimator based on the least squares method (DCE-LSM) is introduced, and since the overhead time is too large, a synchronous sampling-based direct current estimator (SS-DCE) method is subsequently presented. The most obvious feature of the SS-DCE is the current sampling instant that is taken at the synchronized triangle wave of PWM in the bistate switching PA. 
The rest of this study is organized as follows: Section 2 presents the position estimation method for direct current data. Section 3 discusses the simulation/experimental results and checks the static/dynamic performances of the proposed self-sensing estimator. Finally, in Section 4, the conclusions are summarized, and a short future outlook is mentioned.

\section{Methodology}

\subsection{Research Framework}

To restrain the phase shift in the position estimator and improve the system performance and stability, a self-sensing research framework is proposed herein (Figure 6). In step 1, the closed-loop controller with a reference position sensor is set up, and the systematic parameters, which comprise the bias current, the current/position signal amplifier's gain, the anti-alias filters, the PID controller parameters, etc., are tested and recorded. Then, the basic work framework of the AMBs is implemented. In step 2, the self-sensing framework is applied in the AMBs. Compared to the ideal sensor, the position estimators' performances are measured in a simulation test. The position estimation algorithms include the SS-DCE, DCE-LSM, AFAD and direct current measurement (DCM) methods. In step 3, the experimental results are obtained on a single-DOF rig.

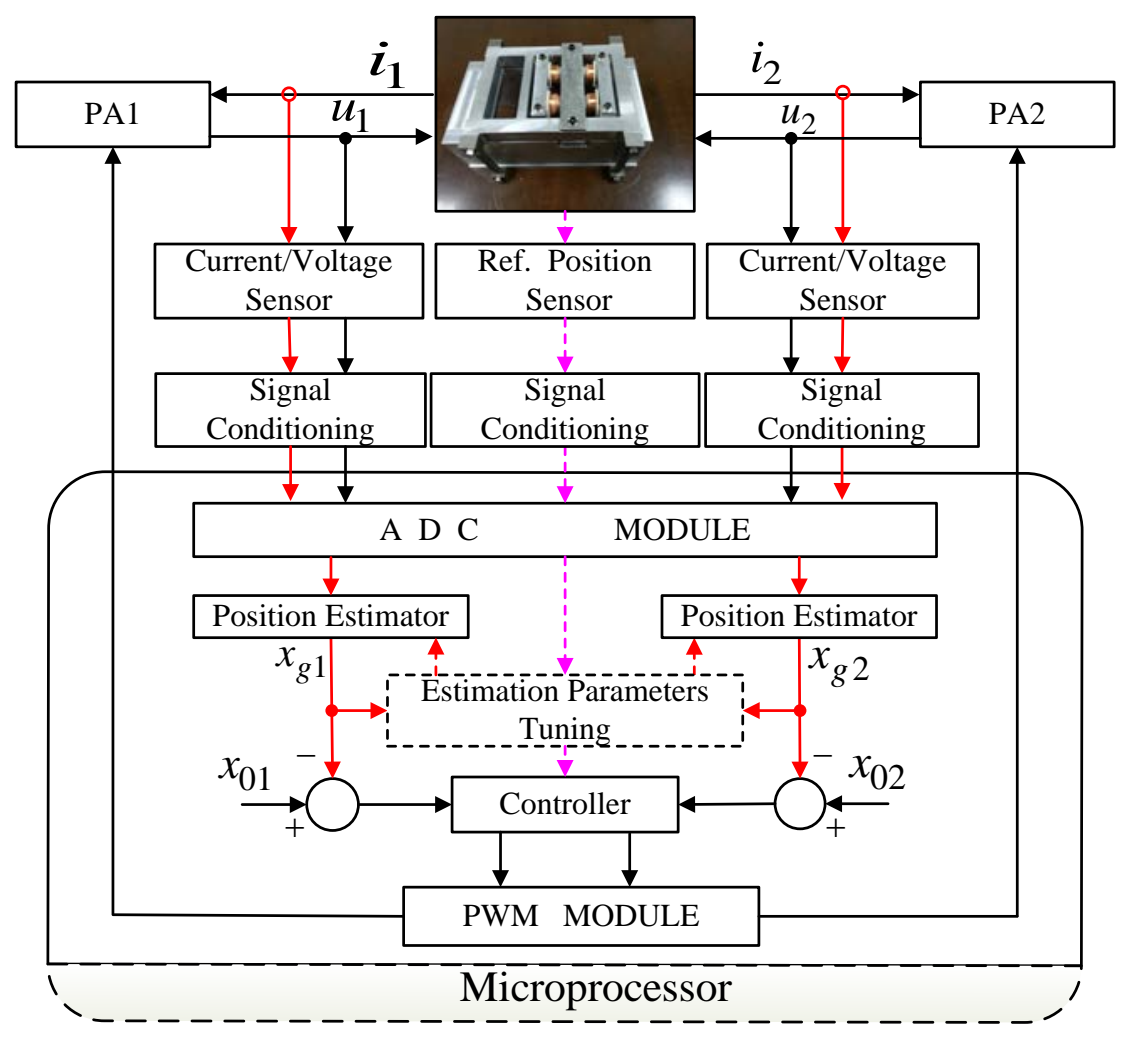

Figure 6. Research framework of the self-sensing AMBs.

\subsection{Amplitude Demodulation Algorithm}

In Figure 7, neglecting the nonlinear magnetic effects (i.e., hysteresis, saturation, eddy current and fringing) and flux leakage, the equivalent reluctance $R_{\mathrm{m}}$ of the overall system is described as

$$
\begin{gathered}
R_{\mathrm{m}}=R_{\mathrm{fc}}+R_{\mathrm{g}}+R_{\mathrm{fr}}=\frac{1}{\mu_{0} A}\left[2\left(g_{0} \pm x\right)+\left(l_{\mathrm{fc}}+l_{\mathrm{fr}}\right) / \mu_{\mathrm{r}}\right] \\
x_{\mathrm{g}}=2\left(g_{0} \pm x\right)+\left(l_{\mathrm{fc}}+l_{\mathrm{fr}}\right) / \mu_{\mathrm{r}}
\end{gathered}
$$

where $R_{\mathrm{fc}}$ is the effective reluctance of the core, $R_{\mathrm{fr}}$ is the reluctance of the rotor, $R_{\mathrm{g}}$ is the reluctance of the gap, $R_{\mathrm{lk}}$ is the reluctance of the leakage fluxes, $l_{\mathrm{fr}}$ and $l_{\mathrm{fc}}$ are the average length of the magnetic 
circuit of the iron rotor and core, respectively, $x$ is the change in the air gap, $g_{0}$ is the initial air gap length, $A$ is the area of the magnetic pole, $l_{\mathrm{lk}}$ is the length of the magnetic flux leakage circuit, $\mu_{0}$ and $\mu_{r}$ are the permeability of air and ferromagnetic materials, respectively and $x_{\mathrm{g}}$ is the estimation position amplitude.
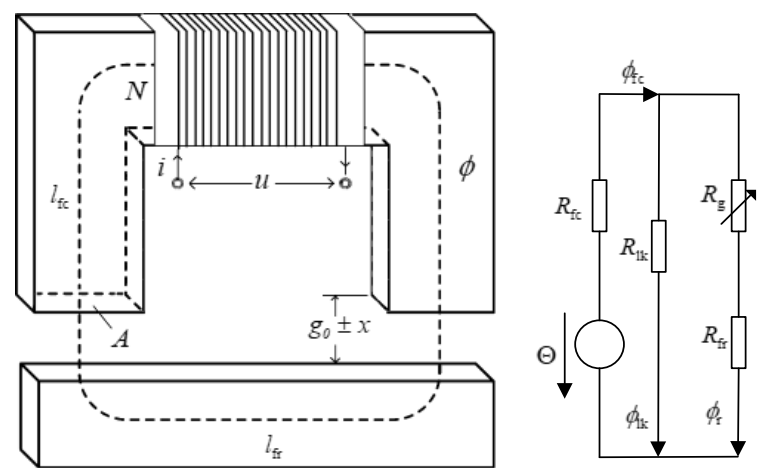

Figure 7. Reluctance model of single-DOF AMB.

According to the Faraday laws of inductance, ampere loop and flux conservation, we can obtain the model control equation as follows:

$$
u-i R=N^{2} \frac{\mathrm{d}\left(i / R_{\mathrm{m}}\right)}{\mathrm{d} t}=L\left(x_{\mathrm{g}}\right) \frac{\mathrm{d} i}{\mathrm{~d} t}+i \cdot \frac{\partial L\left(x_{\mathrm{g}}\right)}{\partial x_{\mathrm{g}}} \frac{\mathrm{d} x_{\mathrm{g}}}{\mathrm{d} t},
$$

where $L=L\left(x_{\mathrm{g}}\right)=K_{\mathrm{N}} / x_{\mathrm{g}}, K_{\mathrm{N}}=\mu_{0} N^{2} A, u$ is the working voltage of the coil, $i$ is the working current, $N$ is the number of individual coil turns, and $R$ is the electrical resistance. Then, the gradient of the current can be expressed as

$$
\frac{\mathrm{d} i}{\mathrm{~d} t}=\frac{1}{L\left(x_{\mathrm{g}}\right)}\left(u-i R-i \cdot \frac{\partial L\left(x_{\mathrm{g}}\right)}{\partial x_{\mathrm{g}}} \frac{\mathrm{d} x_{\mathrm{g}}}{\mathrm{d} t}\right) .
$$

Assuming that the rotor vibration is slow compared to the high-frequency coil current and that the coil resistance is far less than the coil inductive impedance, we can neglect the derivative term of the rotor position and coil resistance. The rotor position is described by

$$
x_{\mathrm{g}}(t)=\frac{K_{\mathrm{N}}}{2 u} \frac{\mathrm{d} i}{\mathrm{~d} t} .
$$

The integral of Equation (4) can be written as

$$
i=\frac{2 x_{\mathrm{g}}(t)}{K_{\mathrm{N}}} \int u d t .
$$

If the switching fundamental ripple $i_{1}(t)=i_{1 \mathrm{~d}} \cos \left(\omega_{\mathrm{s}} t\right)$ and $u_{1}(t)=u_{1 \mathrm{~d}} \sin \left(\omega_{\mathrm{s}} t\right)$, the estimation position amplitude is expressed as

$$
x_{\mathrm{g}}=\omega_{\mathrm{s}} K_{\mathrm{N}} \cdot \frac{i_{1 \mathrm{~d}}}{u_{1 \mathrm{~d}}}=K_{\mathrm{A}} \cdot \frac{i_{1 \mathrm{~d}}}{u_{1 \mathrm{~d}}} .
$$

Equation (6) is the conventional solution of the position estimation approach $[16,50,51]$ as the amplitude demodulation approach, wherein $\omega_{s}$ is the angular frequency. 
The DCM approach reported by Niemann [46] is a simplistic solution that measures the maximum amplitude of the current fundamental ripple isolated by BPF during a constant $50 \%$ duty cycle. The position estimation of DCM is depicted as

$$
x_{\mathrm{g}}=\frac{-2}{K_{\mathrm{N}} \omega_{s}}\left[\max \left(i_{1}(t)-\operatorname{avg}\left(i_{1}(t)\right)\right)\right]
$$

In the DCM estimation, the current ripple amplitude is measured with a constant $50 \%$ duty cycle each time; thus, voltage $u$ in Equation (3) is constant. Since the switching time is now also fixed, the current gradient becomes proportional to the current amplitude during the measurement cycle.

\subsection{DCE-LSM Algorithm}

The switching current of PA is controlled by a duty cycle, and the flux of AMBs is always regulated by the switching current. Assuming that the rotor vibration position is represented by a sinusoid function $x_{m} \sin \omega_{c} t$, the duty cycle's function can be described as $\alpha_{k}=\alpha_{0} \pm \alpha_{m k} \cos \omega_{c} t$ [14]. Meanwhile, the cosine function [51-54] of the bistate switching voltage and current of the electromagnets in the $k$ th cycle can be expressed as follows:

$$
\begin{aligned}
& u_{k}(t)=V\left(2 \alpha_{0}-1\right)+2 V \alpha_{m k} \cos \left(\omega_{c} t\right)+\sum_{n=1}^{\infty} \frac{4 V}{n \pi}\left|\sin \left(n \pi \alpha_{k}\right)\right| \cos \left(n \omega_{\mathrm{s}} t-n \pi \alpha_{k}\right) \\
& i_{k}(t)=\frac{V\left(2 \alpha_{0}-1\right)}{R}+\frac{2 V \alpha_{m k} \cos \left(\omega_{c} t\right)}{\sqrt{R^{2}+\left(\omega_{c} L\right)^{2}}}+\sum_{n=1}^{\infty} \frac{4 V\left|\sin \left(n \pi \alpha_{k}\right)\right|}{n^{2} \pi \omega_{s} L} \cos \left(n \omega_{\mathrm{s}} t-n \pi \alpha_{k}\right)
\end{aligned}
$$

where $\alpha_{0}$ is a constant for the duty cycle of the bias flux, $\alpha_{m k}$ is the quantity variation, $V$ is the supply voltage of PA, $\omega_{c}$ is the control angular frequency, $\omega_{s}$ is the switching angular frequency and $\alpha_{k} \in(0,1)$.

In Figure 8, the switching voltage and current are shown, and the triangle carrier is drawn as a symmetrical wave that is compared with the reference signal controlling the PWM generator. Avoiding the influence of the switching glitches, the current measurement occurs in the time interval $\left[\mathbf{t}_{I}^{1}, t_{I}^{p}\right]$. The current and change of flux linkage in the charging phase can be described as

$$
\begin{gathered}
i\left(k_{I}\right)=i\left(t_{I}^{1}\right)+\frac{1}{L_{k_{I}}} \int_{t_{I}^{1}}^{k_{I}}(u-R i) \mathrm{d} t \\
\Delta \psi_{k_{I}}=\int_{t_{I}^{1}}^{k_{I}}(u-R i) \mathrm{d} t
\end{gathered}
$$

where $\Delta \psi_{k_{I}}$ is $\Delta \psi\left(k_{I} T_{s}\right)$ with $k_{I}=m_{I}^{1}, \ldots, m_{I}^{p}$ and sampling interval $T_{s p}$.

Then, the change of the discretized flux linkage is given by

$$
\begin{gathered}
\Delta \psi_{k_{I}}=T_{s} \sum_{j=m_{I}^{1}}^{k_{I}-1}\left(u_{j}-R i_{j}\right) \\
\Delta \psi_{m_{s}^{I}}=0
\end{gathered}
$$

where $k_{I}=m_{I}^{1}+1, \ldots, m_{I}^{p}$. The current in Equation (10) reads as

$$
i_{k_{I}}=i_{m_{I}^{1}}+\frac{\Delta \psi_{k_{I}}}{L_{k_{I}}}
$$


Since the measurement noise will lead to very imprecise estimations, the resulting equations cannot be practically resolved. According to Equation (13), the inductance in the charging phase can be theoretically deduced in vector notation, wherein a quadratic measure is used by LSM.

$$
\underbrace{\left[\begin{array}{c}
i_{m_{I}^{1}} \\
i_{m_{I}^{1}+1} \\
\cdot \\
\cdot \\
i_{m_{I}^{\mathrm{p}}}
\end{array}\right]}_{\mathbf{I}_{m I}}=\underbrace{\left[\begin{array}{cc}
1 & \Delta \psi_{m_{I}^{1}} \\
1 & \Delta \psi_{m_{I}^{1}+1} \\
\cdot & \cdot \\
\cdot & \cdot \\
\cdot & \cdot \\
1 & \Delta \psi_{m_{I}^{\mathrm{p}}}
\end{array}\right]}_{\mathbf{S}_{I}} \underbrace{\left[\begin{array}{c}
\widetilde{i}_{m_{I}^{1}} \\
\left(L_{k_{I}}\right)^{-1}
\end{array}\right]}_{\mathbf{O}_{I}}
$$

where $\mathbf{I}_{m I} \in \mathbb{R}^{m_{I}^{1}-m_{I}^{p}+1}$ is the measurement vector of the current in the charging phase, $\mathbf{S}_{I} \in \mathbb{R}^{2 *\left(m_{I}^{1}-m_{I}^{p}+1\right)}$ denotes the regression matrix and $\mathbf{O}_{I} \in \mathbb{R}^{2}$ is the output vector to be determined. To improve the robustness of the estimator and decrease the measurement errors of the current, the estimation $\widetilde{i}_{m_{I}^{1}}$ in vector $\mathbf{O}_{I}$ can replace the initial value $i_{m_{I}^{1}}$ in Equation (14). The approximation $\hat{\mathbf{O}}_{I}$ of the output vector $\mathbf{O}_{I}$ in the least squares sense is given by

$$
\hat{\mathbf{O}}_{I}=\left[\left(\mathbf{S}_{I}\right)^{\mathrm{T}} \mathbf{S}_{I}\right]^{-1}\left(\mathbf{S}_{I}\right)^{\mathrm{T}} \mathbf{I}_{m I}
$$

The estimations for the initial current value $\hat{\vec{i}}_{m_{I}^{1}}=\hat{\mathbf{O}}_{I}^{1}$ and the inductance $\hat{L}_{k_{I}}=T_{s p} / \hat{\mathbf{O}}_{I}^{2}$ are obtained in charging phase I. In the same approach, the estimations for the initial value of the current $\hat{i}_{m_{I I}^{1}}=\hat{\mathbf{O}}_{I I}^{1}$ and the inductance $\hat{L}_{k_{I I}}=T_{s p} / \hat{\mathbf{O}}_{I I}^{2}$ can be obtained in discharging phase II.

If the current ripple is almost triangular and the time derivative of inductance $\dot{L}_{k_{I}}$ or $\dot{L}_{k_{I I}}$ is constant within $\left[\mathrm{t}_{I}^{1}, \mathrm{t}_{I}^{p}\right]$ or $\left[\mathrm{t}_{I I}^{1}, \mathrm{t}_{I I}^{q}\right]$, respectively, the average value of the inductance is defined as

$$
\left\{\begin{array}{c}
\bar{L}_{k_{I}}=\hat{L}_{k_{I}}-\dot{L}_{k_{1}} \frac{\Delta t_{I}}{\Delta i_{I}} \bar{i}_{I} \\
\bar{L}_{k_{I I}}=\hat{L}_{k_{I I}}-\dot{L}_{k_{I I}} \frac{\Delta t_{I I}}{\Delta i_{I I}} \bar{i}_{I I}
\end{array},\right.
$$

where $\frac{\Delta t_{I}}{\Delta i_{I}}=\frac{t\left(\mathrm{t}_{I}^{p}\right)-t\left(\mathrm{t}_{I}^{1}\right)}{i\left(t_{I}^{p}\right)-i\left(\mathrm{t}_{I}^{1}\right)}$ and $\frac{\Delta t_{I I}}{\Delta i_{I I}}=\frac{t\left(t_{I I}^{q}\right)-t\left(\mathrm{t}_{I I}^{1}\right)}{i\left(\mathrm{t}_{I I}^{q}\right)-i\left(\mathrm{t}_{I I}^{1}\right)}$ are the reciprocals of the current derivative $\Delta i / \Delta t$, $\dot{L}_{k_{I}}=\bar{L}_{k_{I}}-\hat{L}_{k_{I}}$ and $\dot{L}_{k_{I I}}=\bar{L}_{k_{I I}}-\hat{L}_{k_{I I}}$ are the estimation errors and $\bar{i}_{I}=\frac{1}{p} \sum_{j=1}^{p} i_{I}^{j}$ and $\bar{i}_{I I}=\frac{1}{q} \sum_{j=1}^{q} i_{I I}^{j}$ are the average current of the charging and discharging phases, respectively. The average value of the inductance in the $k$ th PWM cycle can be yielded as

$$
\bar{L}_{k}=\frac{\bar{L}_{k_{I}} \Delta i_{I} \bar{i}_{I I} \Delta t_{I I}-\bar{L}_{k_{I I}} \Delta i_{I I} \bar{i}_{I} \Delta t_{I}}{\Delta i_{I} \bar{i}_{I I} \Delta t_{I I}-\Delta i_{I I} \bar{i}_{I} \Delta t_{I}} .
$$

If $\Delta t_{I}=\Delta t_{I I}=T_{s p}$ and $\Delta i_{I}=-\Delta i_{I I}$ are assumed, Equation (17) can be simplified to

$$
\bar{L}_{k}=\frac{\bar{L}_{k_{I}}+\bar{L}_{k_{I I}}}{2} .
$$

Estimation for the rotor position is derived from Equation (18) as

$$
\hat{x}_{g 1}=K_{N} / \hat{\bar{L}}_{k}
$$


DCE-LSM obtains better estimation precision of the rotor position [31]. However, its operation is limited in industrial applications due to the time consumed by the algorithm and the electronic circuit costs. The LSM algorithm is essentially a position estimation algorithm using the average inductance in every PWM cycle. Therefore, seeking an equivalent LSM algorithm and a solution with cheaper hardware cost is necessary.

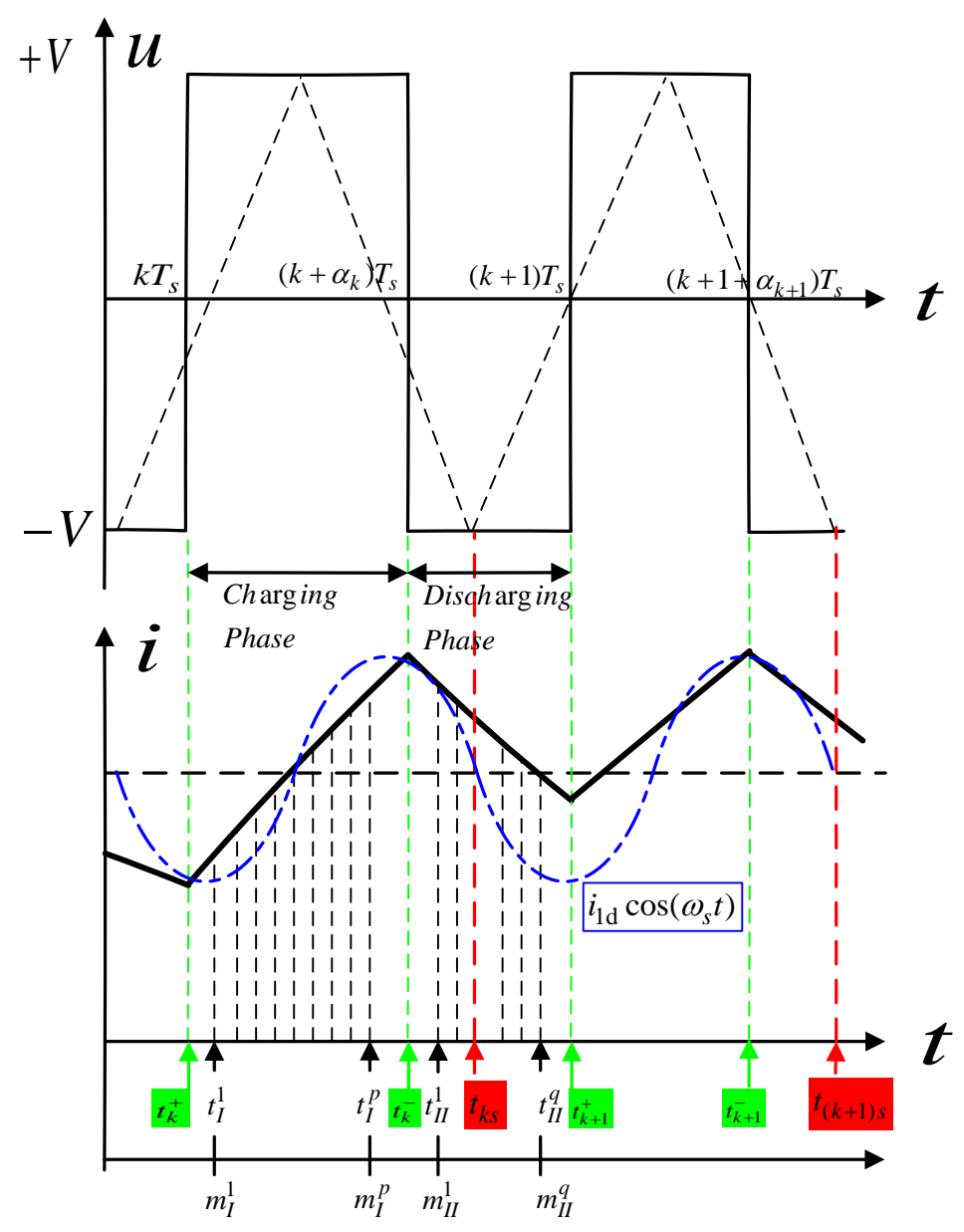

Figure 8. Switching voltage, current and sampling process.

\subsection{SS-DCE Algorithm}

As shown in Figure 8, if the working current is sampled at the instant in the $k$ th PWM cycle,

$$
t_{k s}=k T_{s}+\left(1+\alpha_{k}\right) T_{s} / 2,
$$

Then

$$
\sum_{n=1}^{\infty} \frac{4 V\left|\sin \left(n \pi \alpha_{k}\right)\right|}{n^{2} \pi \omega_{s} L} \cos \left(n \omega_{s} t-n \pi \alpha_{k}\right)=0 .
$$

Equation (8) can be rewritten as

$$
\begin{gathered}
i_{k s}(k)=i_{k}\left(t_{k s}\right)=\frac{V\left(2 \alpha_{0}-1\right)}{R}+\frac{2 V \alpha_{m k} \cos \left(\omega_{c} t_{k s}\right)}{\sqrt{R^{2}+\left(\omega_{c} L\right)^{2}}} \\
i_{k s}(k)=I_{0}+I_{k m} \cos \left(\omega_{c} t_{k s}\right)
\end{gathered}
$$


where $T_{S}$ is the switching period, $I_{0}$ is the bias current $\frac{V\left(2 \alpha_{0}-1\right)}{R}, \alpha_{m k}$ is the quantity variation, $t_{k s}$ is the sampling instant and $I_{k m}$ is the control current amplitude $\frac{2 V \alpha_{m k}}{\sqrt{R^{2}+\left(\omega_{c} L\right)^{2}}}$. Assuming that the control frequency of rotor $\omega_{c}$ is far less than the carrier frequency $\omega_{s}$, we can ensure that $\cos \left(\omega_{c} t_{k s}\right) \neq 0$. Then, the inductive impedance of the coil can be obtained as

$$
L_{k s}=\sqrt{\left(\frac{2 V \alpha_{m k} \cos \left(\omega_{c} t_{k s}\right)}{i_{k s}(k)-I_{0}}\right)^{2}-R^{2}}
$$

Therefore, the rotor position can be depicted as

$$
\hat{x}_{g 2}=K_{N} / L_{k s}
$$

Furthermore, by considering the equations of the $k$ th cycle and the $(k-1)$ th cycle from Equation (22), we can yield the differential current:

$$
i_{k s}(k)-i_{(k-1) s}(k-1)=\frac{\hat{x}_{g 2, k}}{K_{N}}\left[V T_{s}\left(2 \alpha_{k}-1\right)\right] .
$$

Consequently, the estimation for the rotor position is

$$
\hat{x}_{g 2, k}=\frac{V T_{s}\left(2 \alpha_{k}-1\right)}{K_{N}\left[i_{k s}(k)-i_{(k-1) s}(k-1)\right]} .
$$

In Figure 8, during one switching cycle in the time interval $\left[t_{\mathrm{k}}, t_{\mathrm{k}+1}\right]$, two instants, $t_{k}^{+}$and $t_{k}^{-}$, are defined as the moments at which the voltage changes from $-V$ to $+V$ and conversely, respectively. Since the duty cycle for this period is at fixed $\alpha_{k}$ and the symmetrical triangle wave period is $T_{s}$, we can obtain $t_{k}^{-}-t_{k}^{+} \equiv \alpha_{k} T_{s}$ and $t_{k s}$ as

$$
t_{k s}=t_{k}^{+}+T_{s}-T_{s}\left(1-\alpha_{k}\right) / 2=k T_{s}+T_{s}\left(1+\alpha_{k}\right) / 2 .
$$

Assuming $\alpha_{k}=50 \%$, Equation (25) can be rewritten as

$$
i_{k}(k)=i_{k-1}(k-1) .
$$

Briefly, from the above conclusions, the self-sensing SS-DCE process is shorter than the other estimator processes in this study because the signal conditioning the electronic circuits can be canceled, and the operation of the position estimation algorithm is simple. In the digital signal processor, the duty cycle can be provided by the controller, and the symmetrical triangle wave is easy to generate in FPGA (field programmable gate array) or other digital signal process chips from Texas Instruments Incorporated.

Equations (24) and (26) are both formulas of the rotor position. Equation (26) is limited since the current change of the steady state is smaller than that of the transient state. Equation (26) may overflow if the $\mathrm{AD}$ convector cannot distinguish the adjacent sampling current. Another issue may occur when $i_{k}(k)=i_{k-1}(k-1)$ and, simultaneously, $\alpha_{k}=50 \%$. That is, the SS-DCE estimator will fail if the force on the rotor is constant. Consequently, Equation (24) must dominate in the running system and Equation (26) must somehow supplement, e.g., the rotor uprising or landing.

Equation (28) can be a holder of the sampling current, which is obtained with the $50 \%$ duty cycle. Furthermore, the coil current is kept unchanged during this time, which helps coordinate with the mechanical system. Upon insertion of one or more $50 \%$ control cycles, the rotor vibration would be regulated. 


\section{Results and Discussion}

\subsection{Experimental Platform}

To verify the effectiveness of the proposed method, a platform for the experimental AMB was developed herein based on SS-DCE and dual closed-loop control. The experimental platform comprised a controller based on digital signal processor TMS320F2812, a micropositioning platform, current sensor LEM HX-05P, switching PAs and a referring position sensor HZ-891. The micromotion displacement platform was composed of a base, a truss and a flexible hinge. The double-parallel four-bar flexible hinge supported the truss, and the rotor was embedded and fixed on the truss, as shown in Figure 9. The double-parallel four-bar flexible hinge mechanism adopted a symmetrical design on both sides. When the displacement in the horizontal direction was caused by force, the displacements on both sides of the hinge in the vertical direction were equal, which produced strict translation. This could ensure the stability of the single-DOF magnetic bearing in the vertical direction.

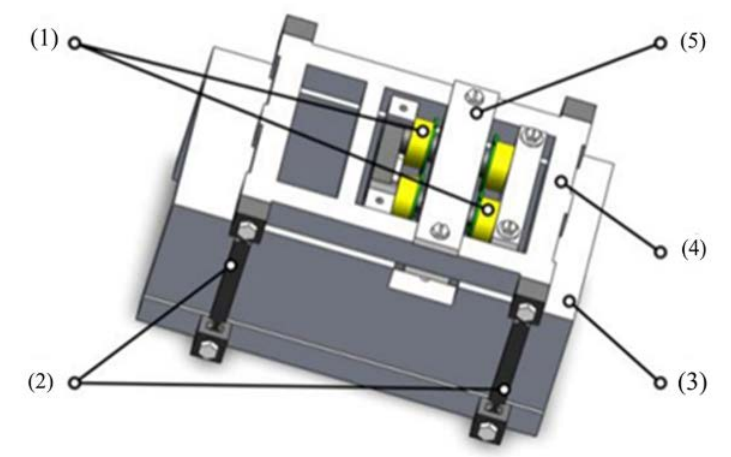

Figure 9. Micromotion displacement platform system. (1) electromagnetic coil; (2) flexible hinge; (3) pedestal; (4) truss; (5) lower rotor.

As shown in Figure 10, the flexible hinge adopted a straight circular-cut flexible hinge structure design, and the material was carbon steel. The specific parameters are shown in Table 1:

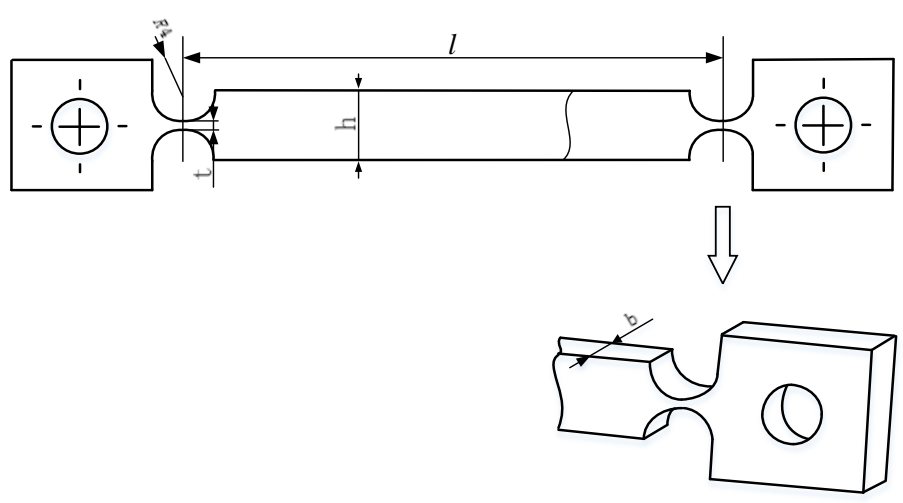

Figure 10. Straight circular-cut flexible hinge structure.

Table 1. Flexible hinge parameters for the AMB.

\begin{tabular}{cc}
\hline Parameters & Values \\
\hline Elastic modulus: $E / G p a$ & 196.2 \\
Width of flexible hinge: $\mathrm{b} / \mathrm{mm}$ & 14 \\
Height of flexible hinge: $\mathrm{h} / \mathrm{mm}$ & 9 \\
Minimum thickness of flexible hinge: $\mathrm{t} / \mathrm{mm}$ & 1 \\
Notch radius: $\mathrm{R} / \mathrm{mm}$ & 4 \\
Mechanism length: $\mathrm{l} / \mathrm{mm}$ & 69 \\
\hline
\end{tabular}


The rigidity formula of the flexible hinge's four-bar mechanism is

$$
K=\frac{8 E b t^{5 / 2}}{9 \pi R^{1 / 2} l^{2}} .
$$

Calculated with specific parameters, $K=0.0816 \mathrm{~N} / \mathrm{m}$. Since the micromotion displacement platform adopts the structure of a double-parallel four-bar flexible hinge, the total stiffness iwass $2 K=0.1632 \mathrm{~N} / \mathrm{m}$.

The experimental platform used an intelligent power module (PM10CSJ060) designed for power switching applications at 2-kHz frequencies. PAs are configured in two-state modes $( \pm 50 \mathrm{~V})$ to ensure high-frequency ripples and increased the working stability of the self-sensing AMB. The built-in control circuits provided the optimum gate drive and protection for the power devices. The experimental platform entity is shown in Figure 11. In Table 2, the main parameters of the experimental self-sensing $\mathrm{AMB}$ are listed. The force/displacement factor $k_{\mathrm{x}}$ is calculated by [55].

$$
k_{x}=-\frac{\mu_{0} N^{2} A I_{0}^{2}}{2 g_{0}^{3}}=-2.8 \times 10^{4} N / m
$$

A vital part of SS-DCE is a synchronized-sampling event, which is implemented in the timer underflow interrupt T1UFINT/T3UFINT of the EVA/EVB of TMS320F2812. Since the interrupt occurs at instant $t_{k s}$, obtaining the current synchronized with the PWM signal is not difficult.

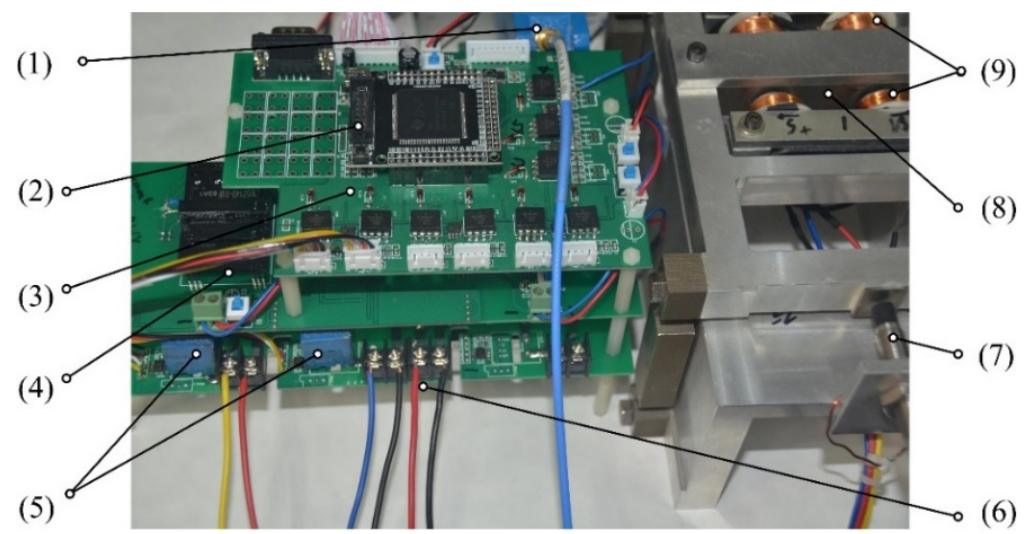

Figure 11. Self-sensing AMB's experimental platform. (1) Reference sensor amplifier; (2) controller board; (3) signal process board; (4) power board; (5) PA board; (6) current sensor; (7) reference sensor HZ-891; (8) rotor; (9) electromagnets.

Table 2. Parameters of single-DOF AMB.

\begin{tabular}{cc}
\hline Parameters & Values \\
\hline Single magnetic pole area: $A / \mathrm{cm}^{2}$ & 6.16 \\
Coil number: $N /$ turns & 50.00 \\
Initial gap: $g_{0} / \mu \mathrm{m}$ & $6.76 \times 10^{2}$ \\
Rotor mass: $m / \mathrm{kg}$ & 1.93 \\
Relative permeability: $\mu_{\mathrm{r}}$ & $2.30 \times 10^{3}$ \\
Coil resistance: $R / \Omega$ & 0.50 \\
Nominal inductance: $L_{0} / \mathrm{mH}$ & 13.20 \\
PWM frequency: $f_{s} / \mathrm{kHz}$ & 2.00 \\
Sampling frequency of DFAD $/ \mathrm{DCM} / \mathrm{LSM}: / \mathrm{kHz}$ & 100.00 \\
Bias current: $I_{0} / \mathrm{A}$ & 3.00 \\
Force/displacement factor: $k_{\mathrm{x}} /(\mathrm{N} / \mathrm{m})$ & $-2.8 \times 10^{4}$ \\
Natural frequency of test $\mathrm{rig}: / \mathrm{Hz}$ & 19.26 \\
\hline
\end{tabular}


In this study, the simulation and experimental resulted were compared with several other estimation algorithms, including the DFAD approach, DCM approach and DCE-LSM and SS-DCE position estimation approaches. The current and voltage signals were digitized via a $100-\mathrm{kHz}$ A/D converter when filtered by the analog BPFs that isolate the fundamental component to improve the sampling resolution. Then, the ideal absolute value functions were implemented to detect the envelope of the fundamental component of the current and voltage, and the position information was shifted to low frequencies. LPFs can select only low-frequency baseband signals as the control signal. An FIR filter was employed in the digital signal processor.

The Bode plots of BPF are shown in Figure 12. The band-pass of 30-, 50- and 300th order BPFs was $0.3-0.5 \pi$ when the sample frequency fs $=10 \mathrm{kHz}$. The 30th order filter precision was the lowest level, but its phase lag was the smallest; the 300th order filter precision was the highest level, but its phase lag was the largest. When the sample frequency fs $=100 \mathrm{kHz}, \mathrm{BPFs}$ ' Bode plots were noticeably closer to the corresponding LPFs. Accordingly, BPF could be replaced by LPF in practice because the former had a low-pass effect and the fundamental ripple was just $2 \mathrm{kHz}$. The Bode plots of the last LPF were shown in Figure 13, from which similar conclusions could be drawn. The 30th order filters of BPF and LPF were qualified for the self-sensing process. The 50-Hz working currents by sensor, BPF and LPF in the DFAD estimator were shown in Figure 14. Since the power frequency was $50 \mathrm{~Hz}$, the noise and disturbance of $50 \mathrm{~Hz}$ were obvious, and significantly, the self-sensing estimator was tested at $50 \mathrm{~Hz}$.

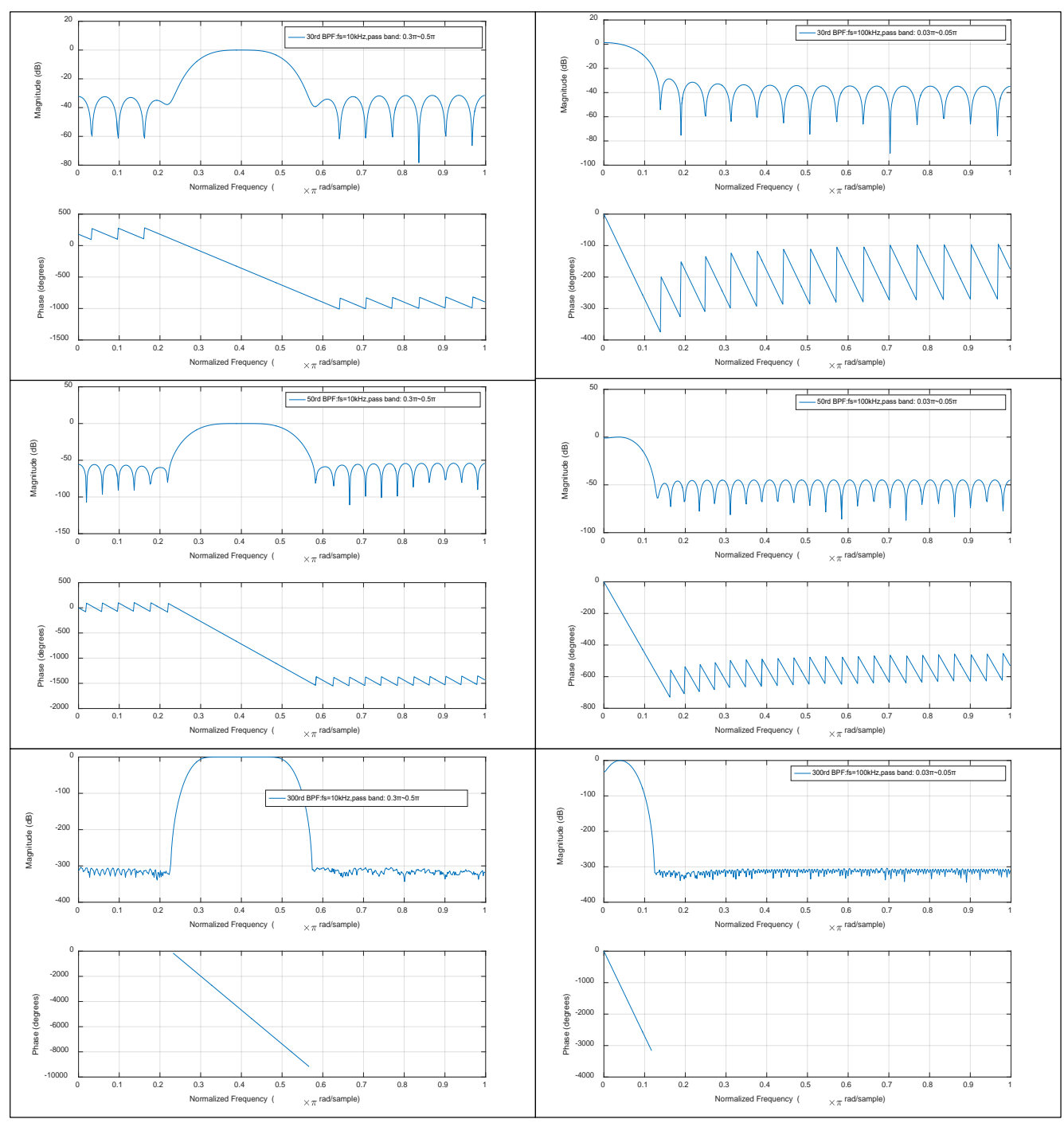

Figure 12. Bode plots of 30-, 50- and 300th order BPF with different sample frequencies. 


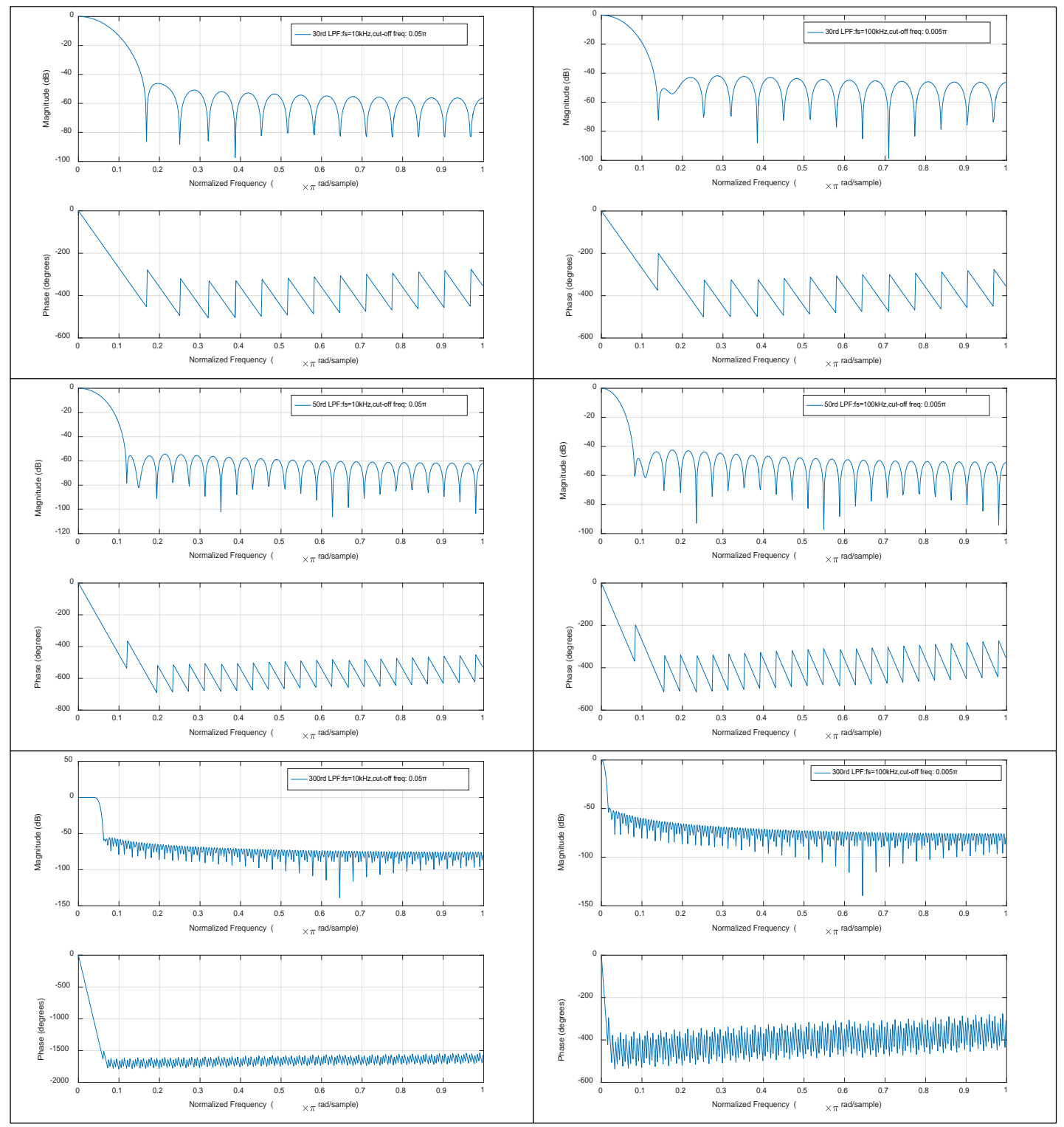

Figure 13. Bode plots of 30-, 50- and 300th order LPF with different sample frequencies.

Thereafter, the rotor position can be calculated by the quotient of the max value of the current and voltage and be compensated by the nonlinearity of magnetic material as

$$
1 / \mu_{r}=\mathrm{a}_{\mathrm{m} 2} B^{2}+\mathrm{a}_{\mathrm{m} 1} B+\mathrm{a}_{\mathrm{m} 0},
$$

where $a_{m} a_{m}$ and $a_{m}$ are the coefficients of the quadratic polynomial that are determined via the simple experiments reported by Schammass [16], magnetic flux density $B$ is obtained by $\mu_{0} N i_{\mathrm{L}} / 2 x_{\mathrm{g}-1}$ and $x_{\mathrm{g}-1}$ is the prior value of the estimator output. In Table 3 , the self-sensing parameters for AMB are listed. The PD and PI controller parameters are tuned based on the extended critical proportion method. The slight difference in the estimator convergence rate stems from the control parameters. For example, the SS-DCE convergence rate when $K_{d}=10$ and $K_{d}=22$ is lower than that when $K_{d}=20$ and $K_{d}=45$; however, $K_{d}$ cannot be over 68 . Thus, the frequency of the first closed-loop mode of the test rig is obtained:

$$
\begin{gathered}
\omega_{e c} \approx \sqrt{-\left(K_{x}+K_{p} \cdot K_{i}\right) / m}=1242.60 \\
\quad \text { or } f_{e c}=\omega_{e c} /(2 \pi)=197.77 \mathrm{~Hz}
\end{gathered}
$$



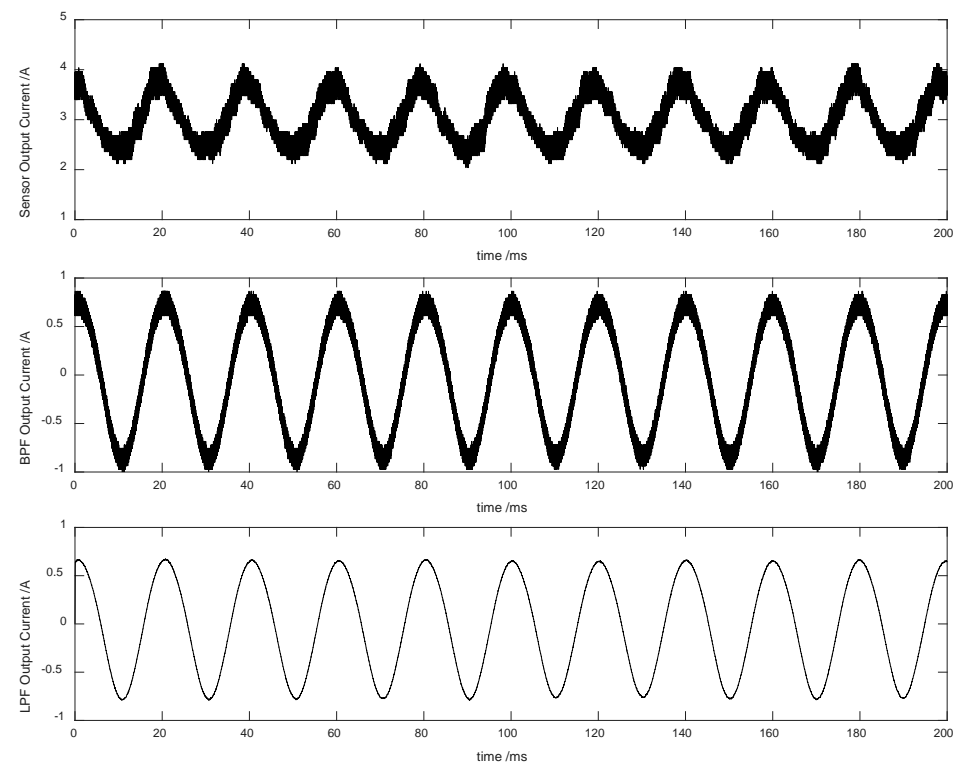

Figure 14. Currents of the DFAD estimator $(50 \mathrm{~Hz})$.

Table 3. Self-sensing parameters of the AMB.

\begin{tabular}{|c|c|c|c|c|c|c|c|}
\hline \multirow{2}{*}{ Estimators } & \multicolumn{2}{|c|}{ Positions (PD) } & \multicolumn{2}{|c|}{ PAs (PI) } & \multicolumn{3}{|c|}{ Compensators } \\
\hline & $K_{\mathrm{p}}(\mathrm{A} / \mathrm{mm})$ & $K_{d}(\mathrm{~A} \cdot \mathrm{s} / \mathrm{m})$ & $K_{\mathrm{p}}$ & $K_{\mathrm{I}}$ & $a_{m 2}$ & $a_{m 1}$ & $a_{m 0}$ \\
\hline DFAD & 10 & 22 & 0.2 & 0.01 & $5.51 \times 10^{5}$ & $-1.92 \times 10^{5}$ & $4.10 \times 10^{6}$ \\
\hline DCM & 20 & 38 & 0.5 & 0.01 & $-2.50 \times 10^{5}$ & $1.03 \times 10^{5}$ & $3.78 \times 10^{6}$ \\
\hline DCE-LSM & 20 & 37 & 0.5 & 0.012 & $-2.50 \times 10^{5}$ & $1.03 \times 10^{5}$ & $3.78 \times 10^{6}$ \\
\hline SS-DCE & 20 & 45 & 0.5 & 0.012 & $-2.50 \times 10^{5}$ & $1.03 \times 10^{5}$ & $3.78 \times 10^{6}$ \\
\hline Sensor & 15 & 32 & 0.2 & 0.01 & - & - & - \\
\hline
\end{tabular}

\subsection{Simulation Results}

A sinusoidal excitation signal with a $10-\mu \mathrm{m}$ peak-peak value was applied as a reference position with a frequency ranging from 20 to $200 \mathrm{~Hz}$. Figure 15 shows the simulation results of the static performances at $20 \mathrm{~Hz}$. In Figure 15a,b, the normalization inductances of the four estimators are depicted with the nominal inductance in a working cycle. The static simulation results of the position estimators are shown in terms of sensor linearity and the error referring to the theoretical result of the AMBs' output. Under open-loop conditions with a constant bias current of $3.0 \mathrm{~A}$, the desired position linearly varied between 50 and $250 \mu \mathrm{m}$. Figure $15 \mathrm{c}$,d shows the estimation position compared to the ideal set value, and the linearity and error of the estimation position are shown in Figure 15e-h. As the estimation error is not discernible in Figure 15e,f, the detailed error is shown in Figure 15g,h. Since the test frequency of $20 \mathrm{~Hz}$ was close to the natural frequency, the output position and error of these estimators were affected by the resonance characteristic of the rotor.

In Figure 15, a minimum error is observed for the DCE-LSM demodulation algorithm in the $50-250 \mu \mathrm{m}$ range. The error of the SS-DCE demodulation algorithm is equivalent to that of DCM. The DCE-LSM demodulation algorithm showed excellent linearity, but its CPU overhead was larger than that of the others. In regards to related research conclusions and a factual working status, the inductance, position, linearity and error parameters in the transition frequency band (50-200 Hz) held important significance to characterize the system performance of the self-sensing AMB. To address the matter, static performances at frequencies of 100, 150 and $200 \mathrm{~Hz}$ were performed, as shown in Figures 16-19. The proposed SS-DCE method could obtain accurate position and inductance estimation results. Compared to the DCE-LSM and DFAD methods, the SS-DCE method conducted better linearity and error in the transition frequency band. In Figure 20, the results of these estimators' precisions 
are outlined in the $0.1-200 \mathrm{~Hz}$ range. Apparently, the SS-DCE method had higher linearity precision, especially for the rising-speed frequency range.

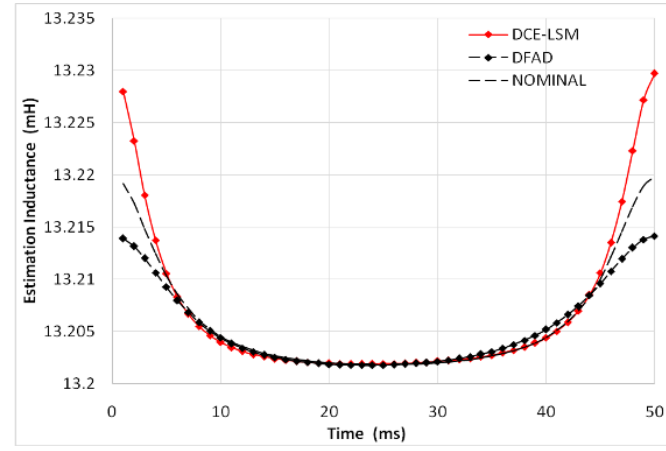

(a) Estimation inductance of DCE-LSM and DFAD

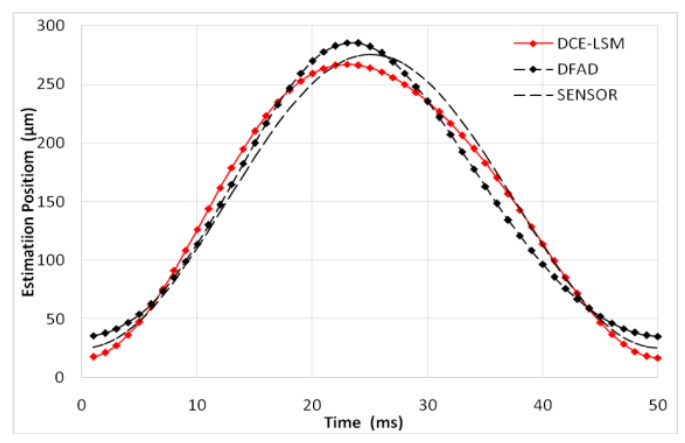

(c) Estimation position of DCE-LSM and DFAD

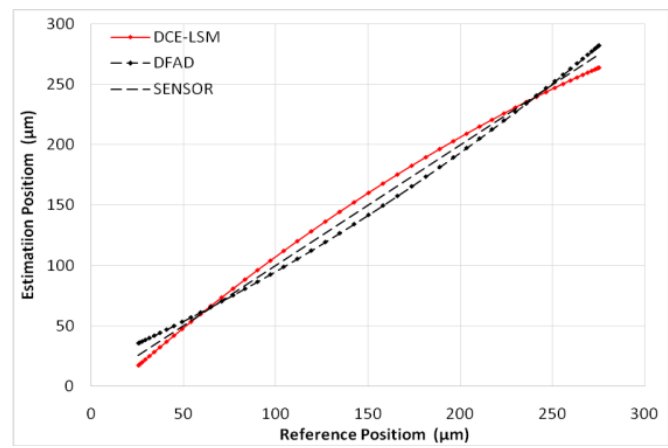

(e) Position linearity of DCE-LSM and DFAD

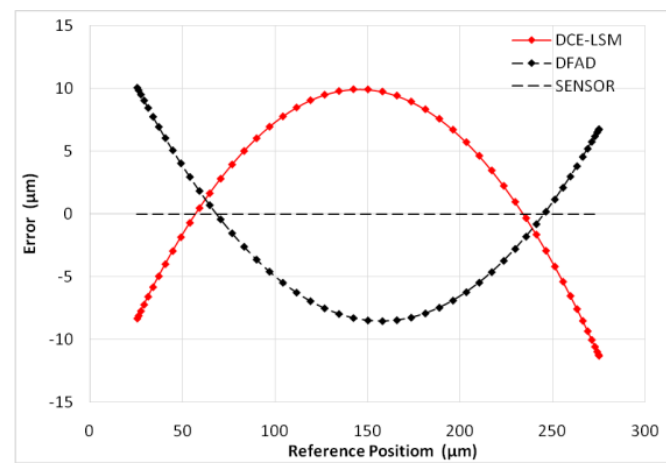

(g) Error of position of DCE-LSM and DFAD

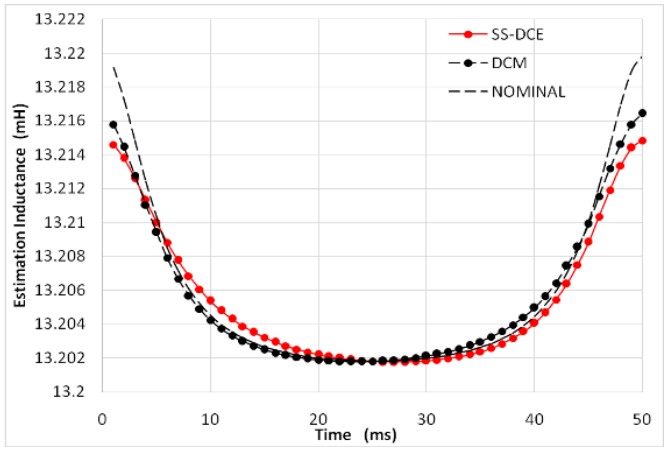

(b) Estimation inductance of SS-DCE and DCM

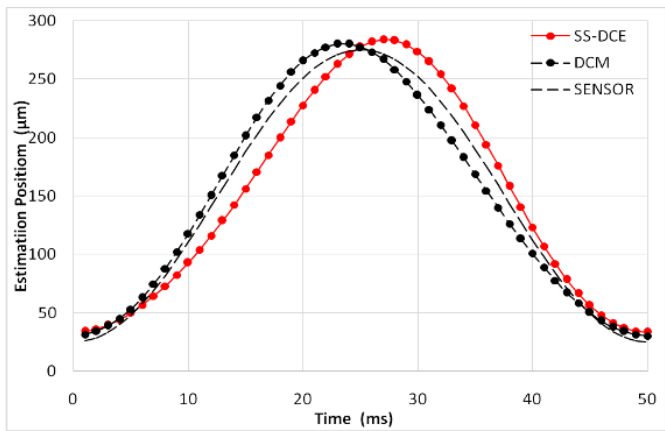

(d) Estimation position of SS-DCE and DCM

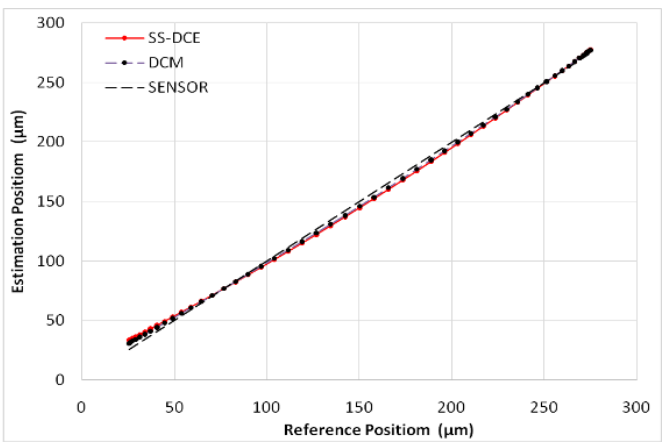

(f) Position linearity of SS-DCE and DCM

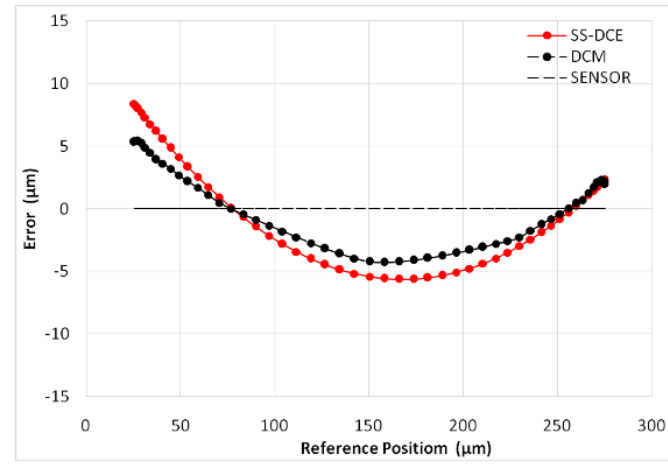

(h) Error of position of SS-DCE and DCM

Figure 15. Static performance simulation results $(20 \mathrm{~Hz})$. 


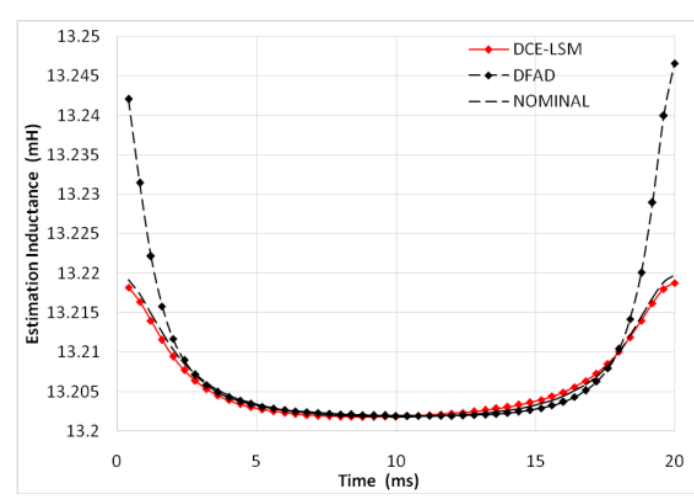

(a) Estimation inductance of DCE-LSM and DFAD

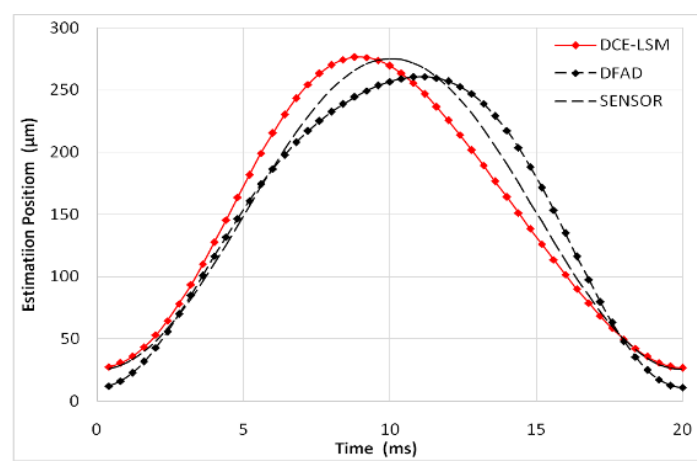

(c) Estimation position of DCE-LSM and DFAD

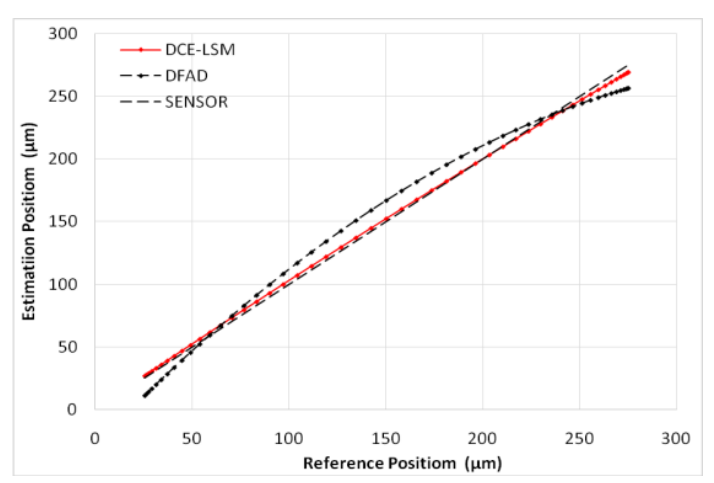

(e) Position linearity of DCE-LSM and DFAD

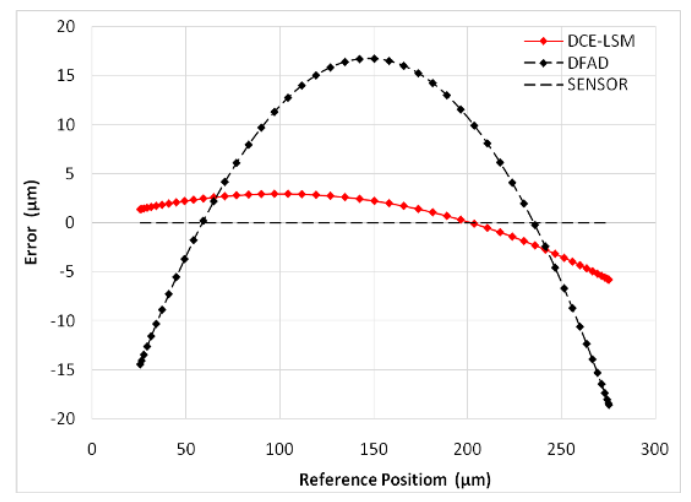

(g) Error of position of DCE-LSM and DFAD

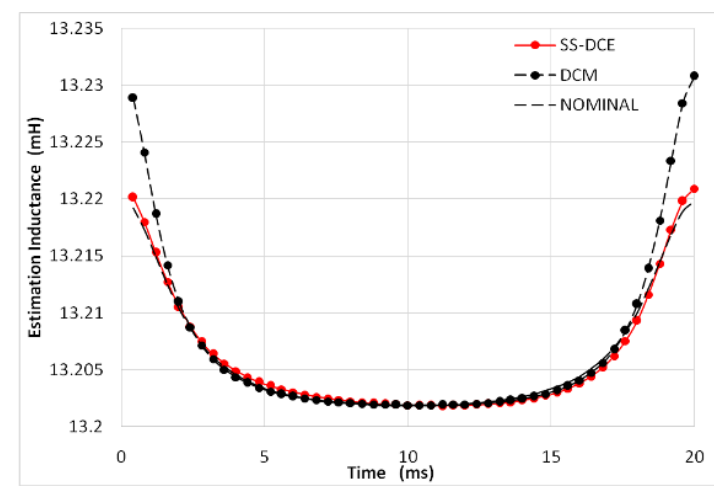

(b) Estimation inductance of SS-DCE and DCM

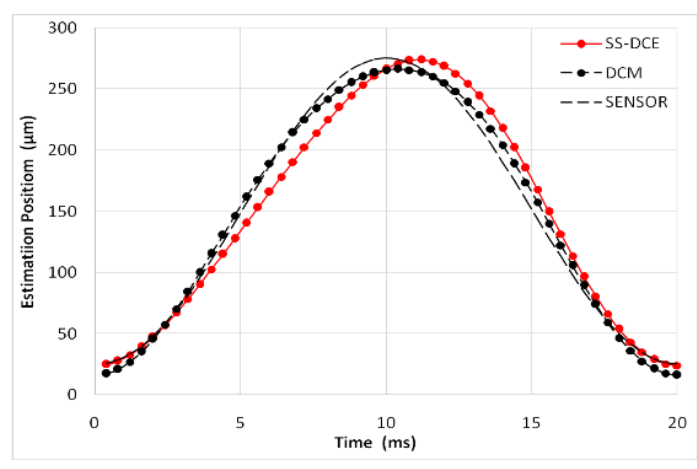

(d) Estimation position of SS-DCE and DCM

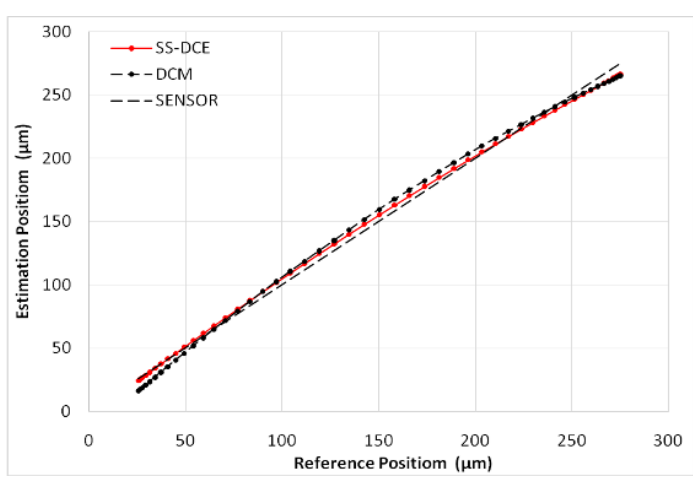

(f) Position linearity of SS-DCE and DCM

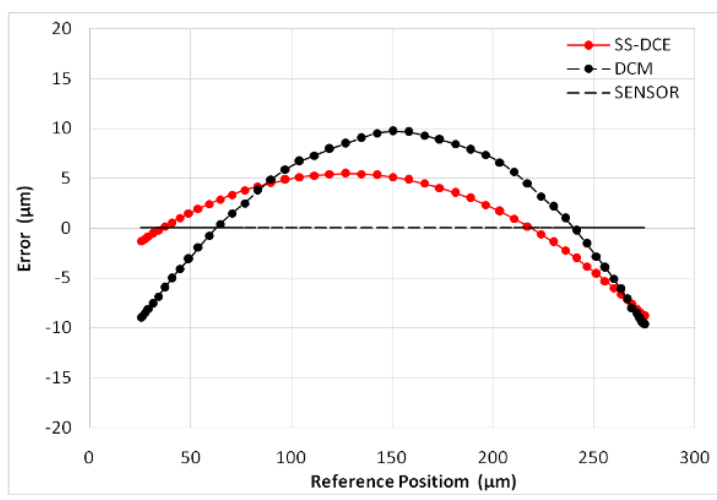

(h) Error of position of SS-DCE and DCM

Figure 16. Static performance simulation results $(50 \mathrm{~Hz})$. 


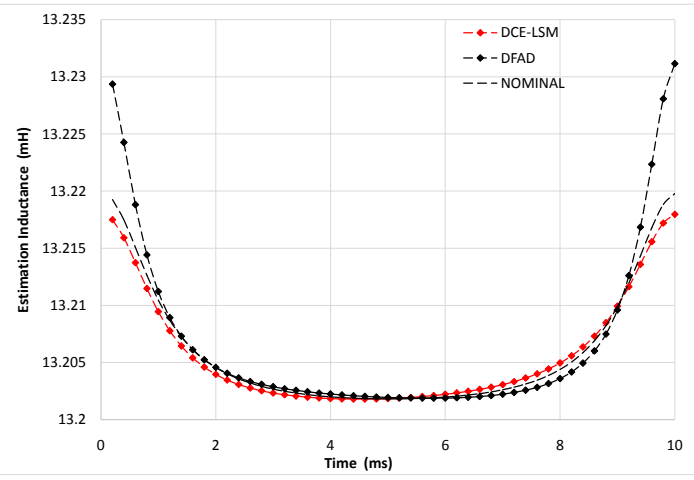

(a) Estimation inductance of DCE-LSM and DFAD

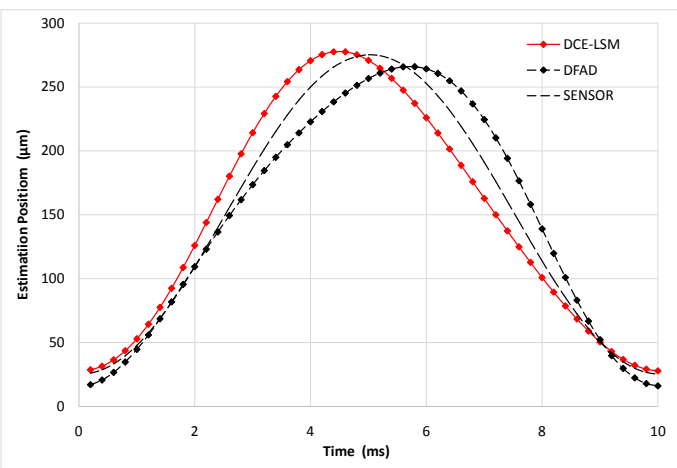

(c) Estimation position of DCE-LSM and DFAD

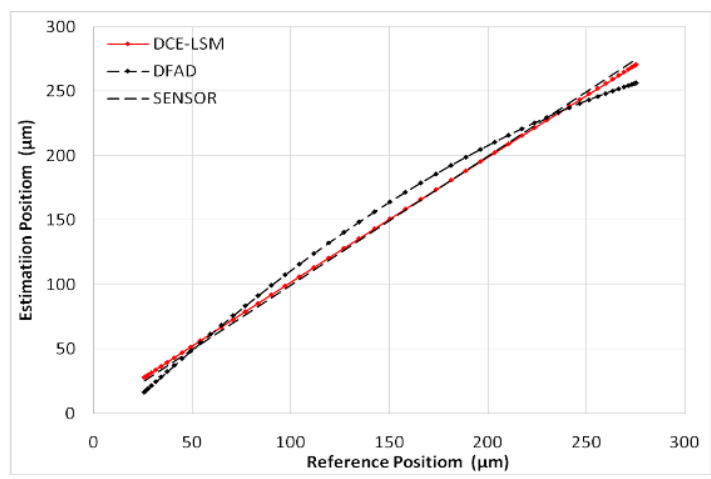

(e) Position linearity of DCE-LSM and DFAD

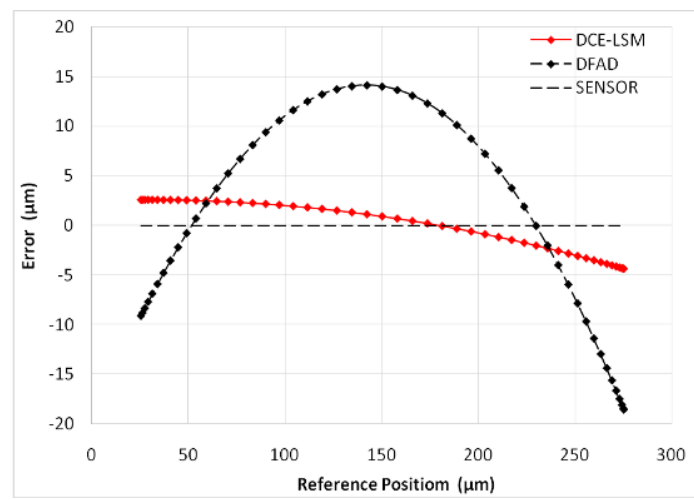

(g) Error of position of DCE-LSM and DFAD

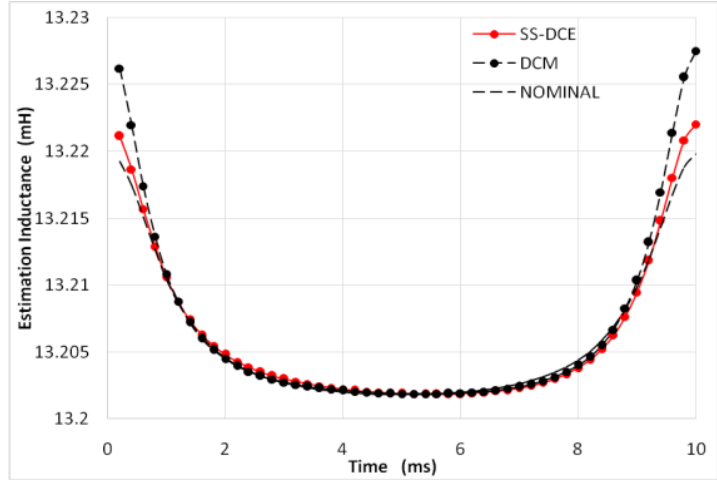

(b) Estimation inductance of SS-DCE and DCM

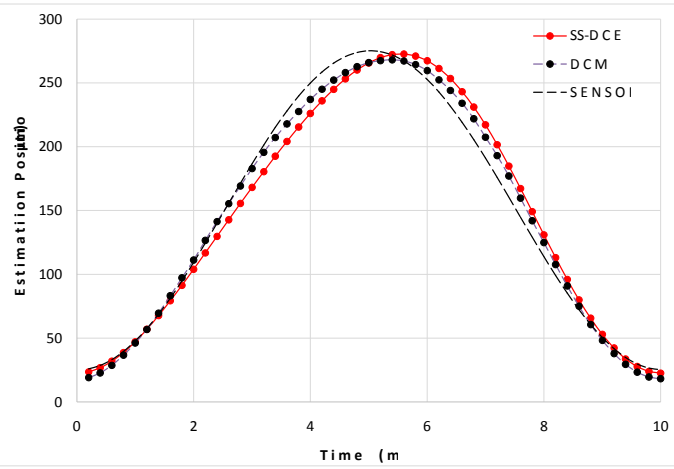

(d) Estimation position of SS-DCE and DCM

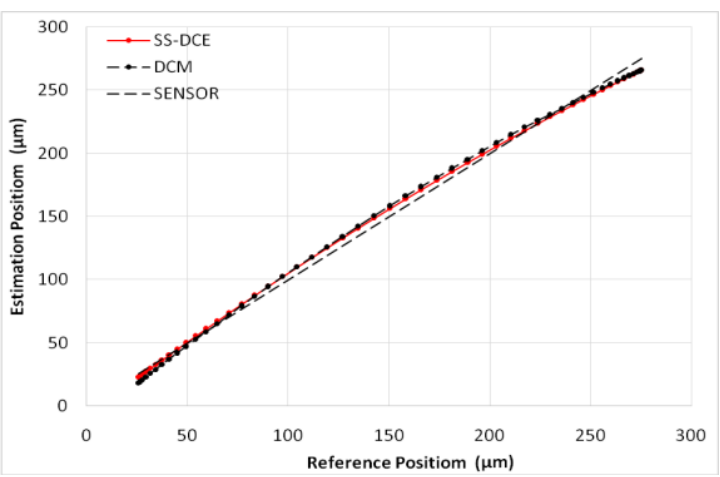

(f) Position linearity of SS-DCE and DCM

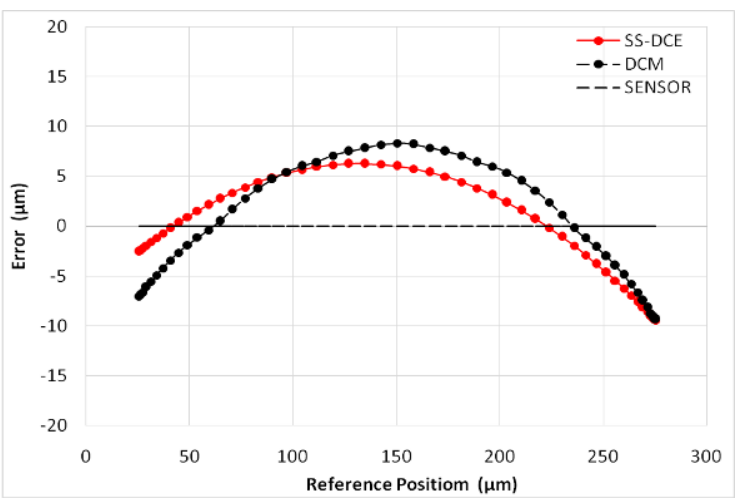

(h) Error of position of SS-DCE and DCM

Figure 17. Static performance simulation results $(100 \mathrm{~Hz})$. 


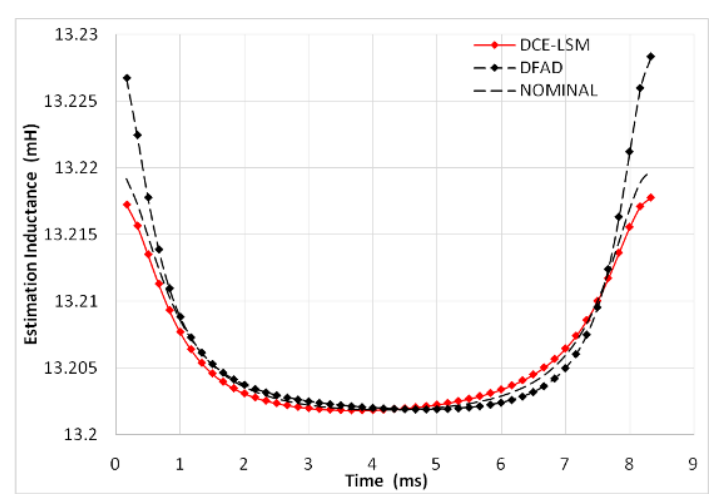

(a) Estimation inductance of DCE-LSM and DFAD

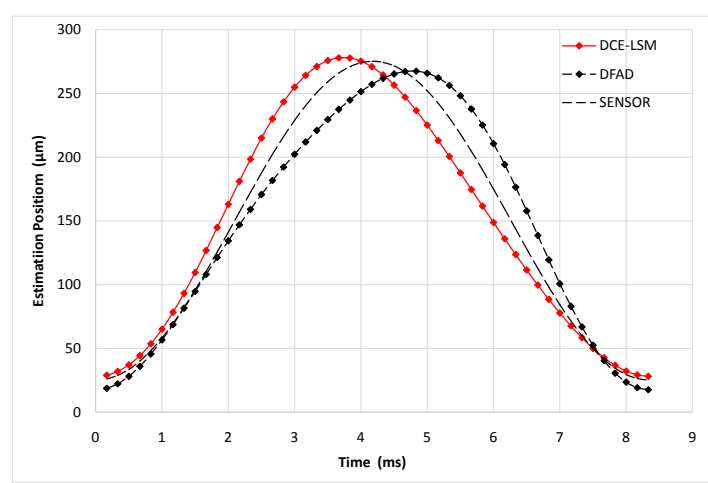

(c) Estimation position of DCE-LSM and DFAD

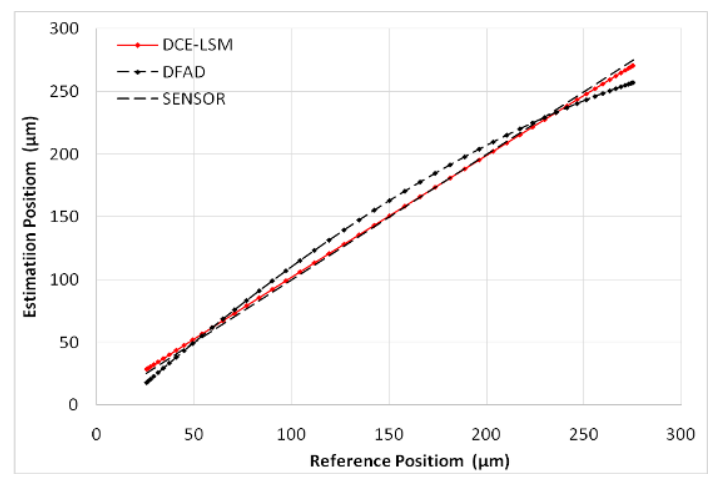

(e) Position linearity of DCE-LSM and DFAD

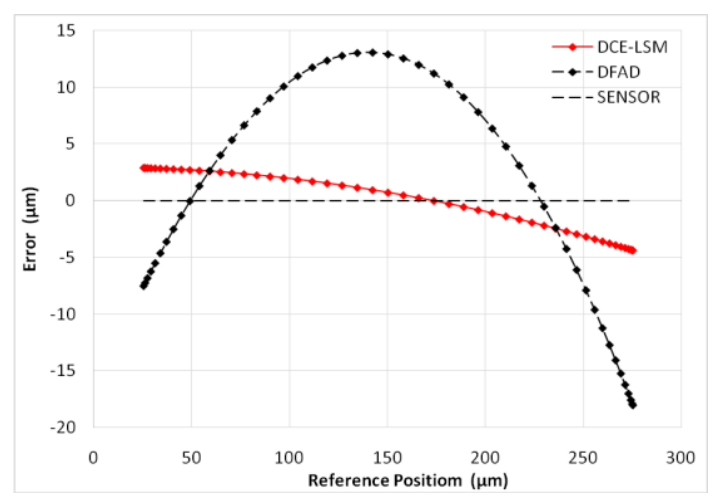

(g) Error of position of DCE-LSM and DFAD

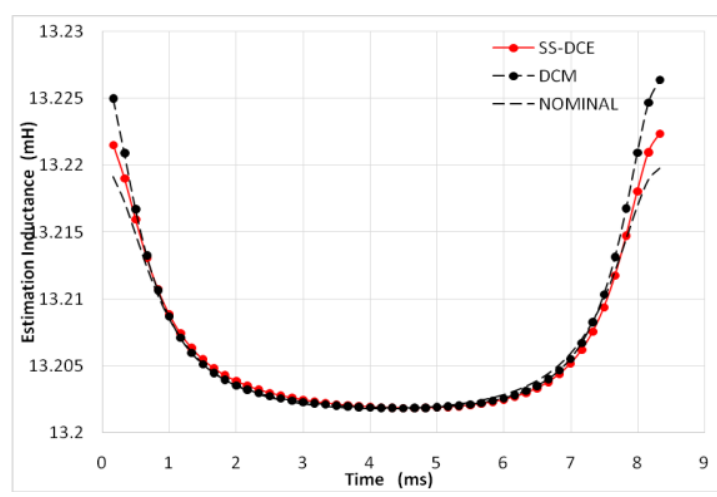

(b) Estimation inductance of SS-DCE and DCM

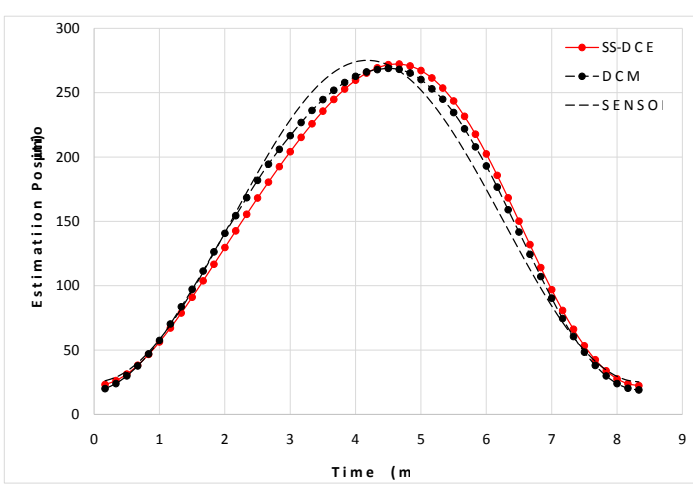

(d) Estimation position of SS-DCE and DCM

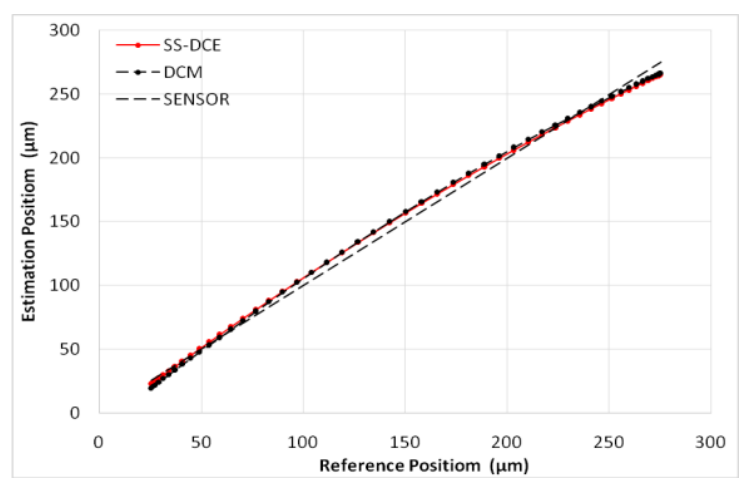

(f) Position linearity of SS-DCE and DCM

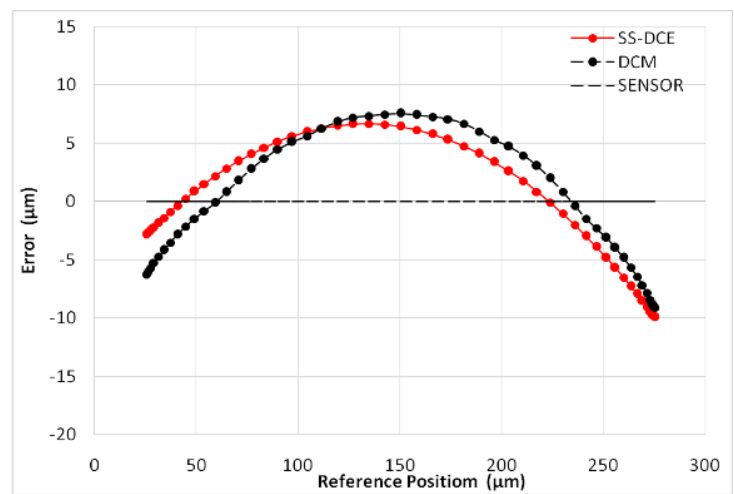

(h) Error of position of SS-DCE and DCM

Figure 18. Static performance simulation results $(150 \mathrm{~Hz})$. 


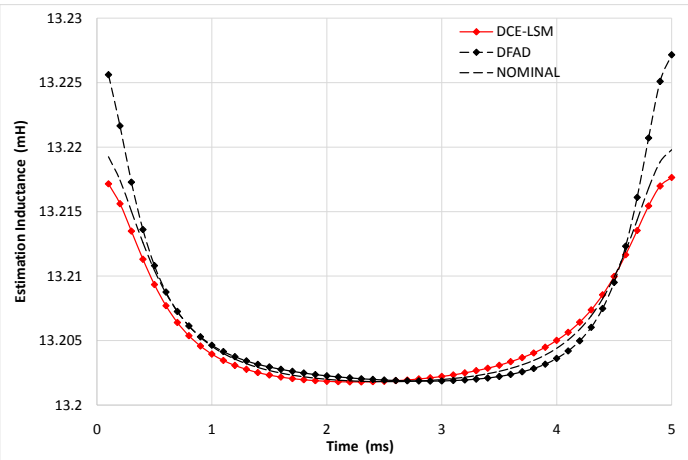

(a) Estimation inductance of DCE-LSM and DFAD

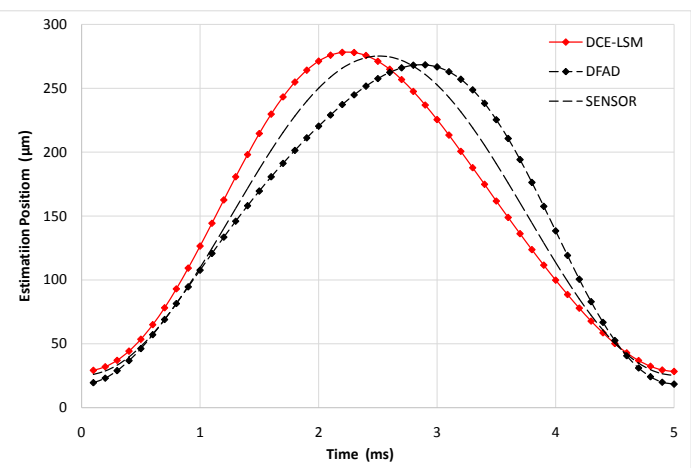

(c) Estimation position of DCE-LSM and DFAD

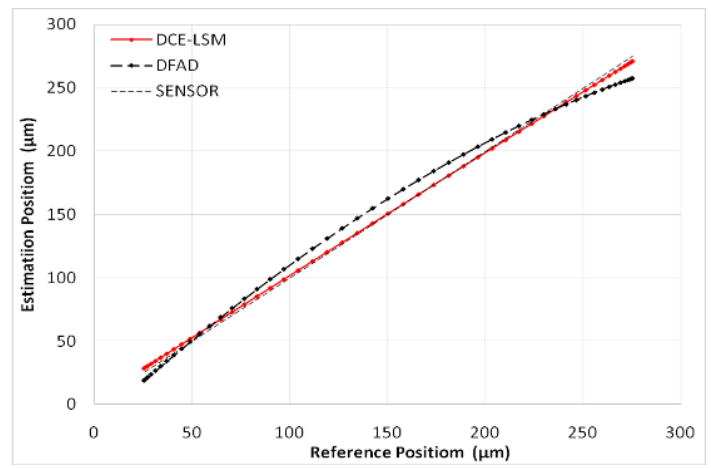

(e) Position linearity of DCE-LSM and DFAD

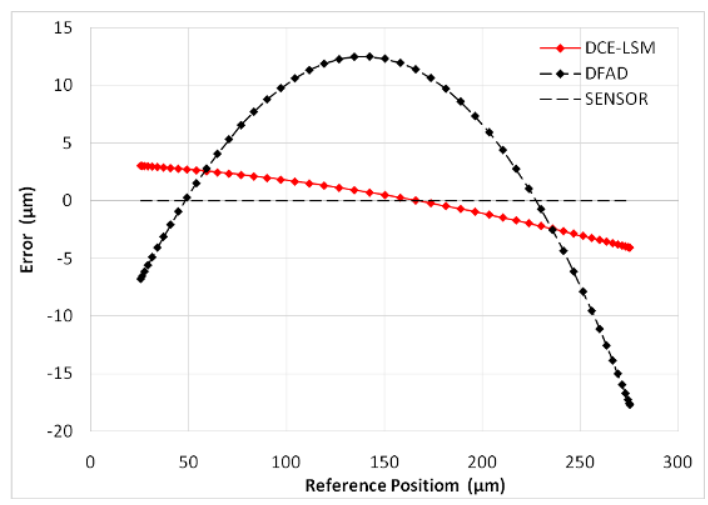

(g) Error of position of DCE-LSM and DFAD

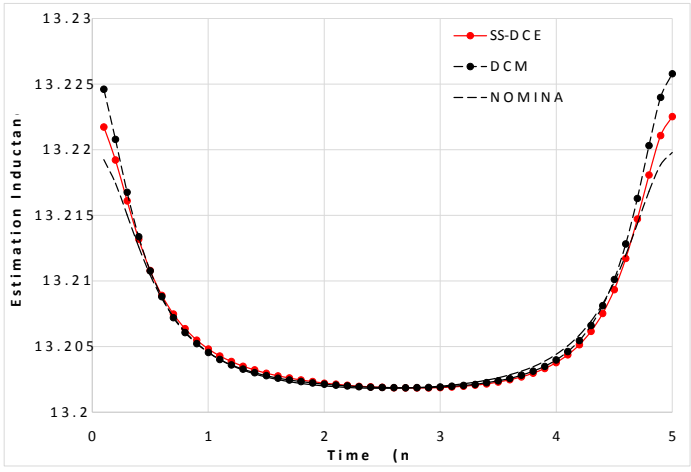

(b) Estimation inductance of SS-DCE and DCM

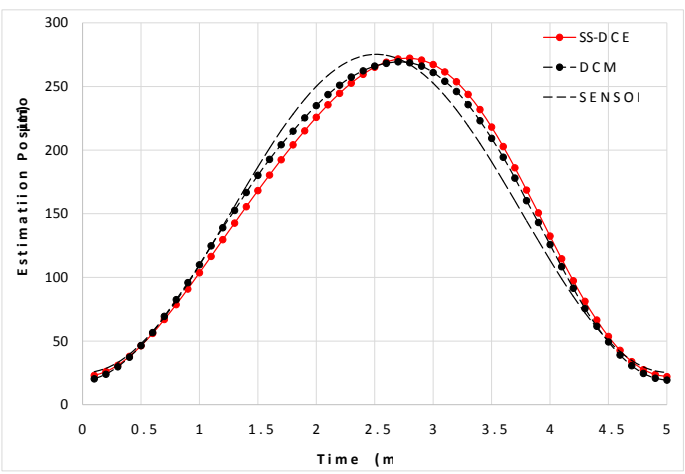

(d) Estimation position of SS-DCE and DCM

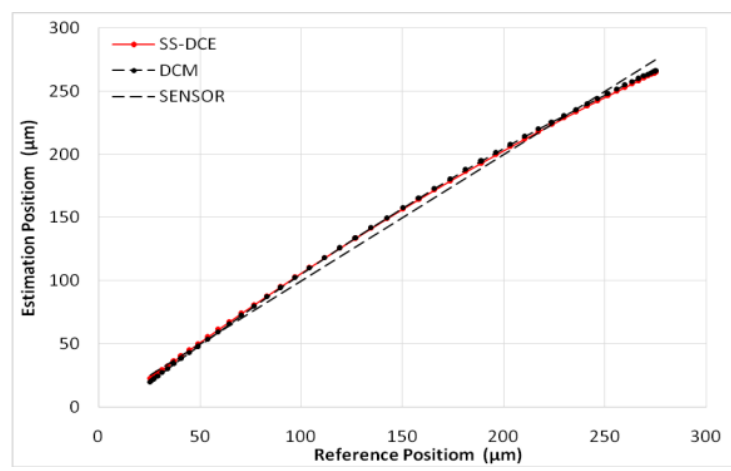

(f) Position linearity of SS-DCE and DCM

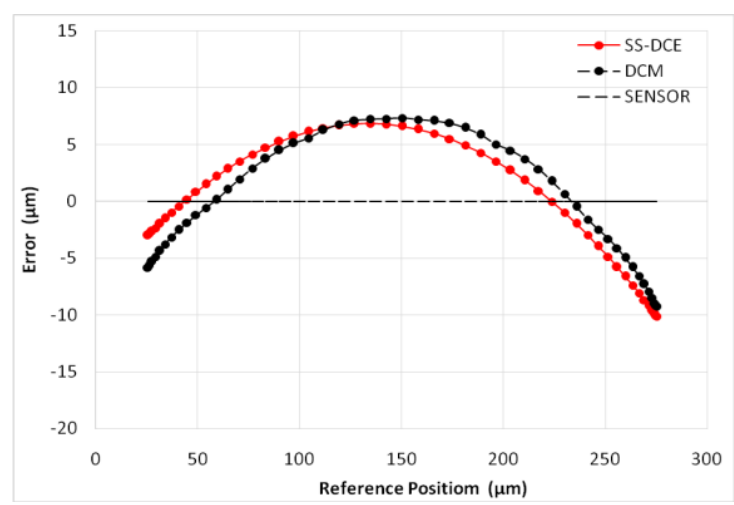

(h) Error of position of SS-DCE and DCM

Figure 19. Static performance simulation results $(200 \mathrm{~Hz})$. 


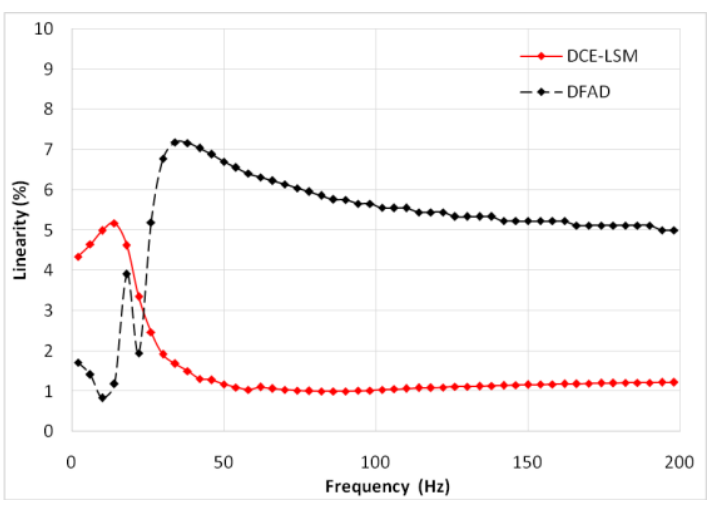

(a) Linearity of DCE-LSM and DFAD

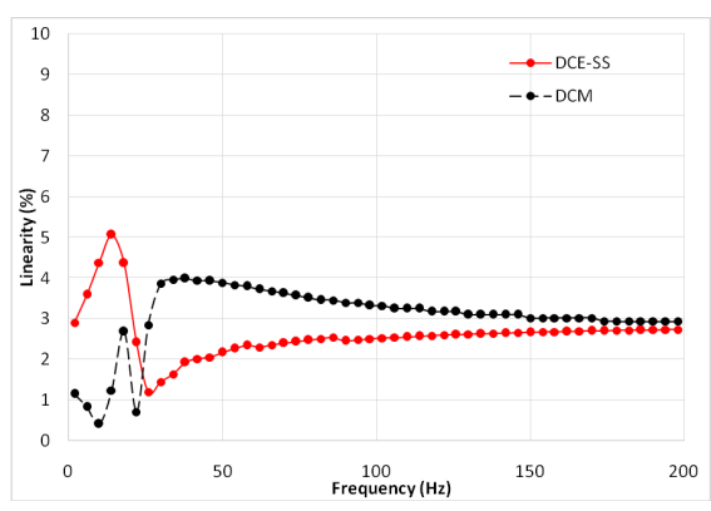

(b) Linearity of SS-DCE and DCM

Figure 20. Simulation results of estimator precision.

Moreover, the above results present that both the DCE-LSM and SS-DCE outputs differed by less than $7.5 \mu \mathrm{m}$ from the reference signal of the theoretical model in the 50-250 $\mu \mathrm{m}$ range when the test frequency was kept away from the natural frequency. This was primarily attributed to the adequate data obtained for estimating the working coil current.

The gain and phase response of the self-sensing system are denoted as

$$
G(\omega)=20 \log \left(X_{d}(\omega) / X_{r}(\omega)\right)
$$

where $X_{d}(\omega)$ is the self-sensing output and $X_{r}(\omega)$ is the reference signal. In Figure 21, the comparative results show that the phase-shift could be clearly reduced by referring to the digital demodulation, demonstrating that the phase lag of SS-DCE was around $-22^{\circ}$ at the natural frequency, but was $-62^{\circ}$ phase margin when the rotor worked at $200 \mathrm{~Hz}$.

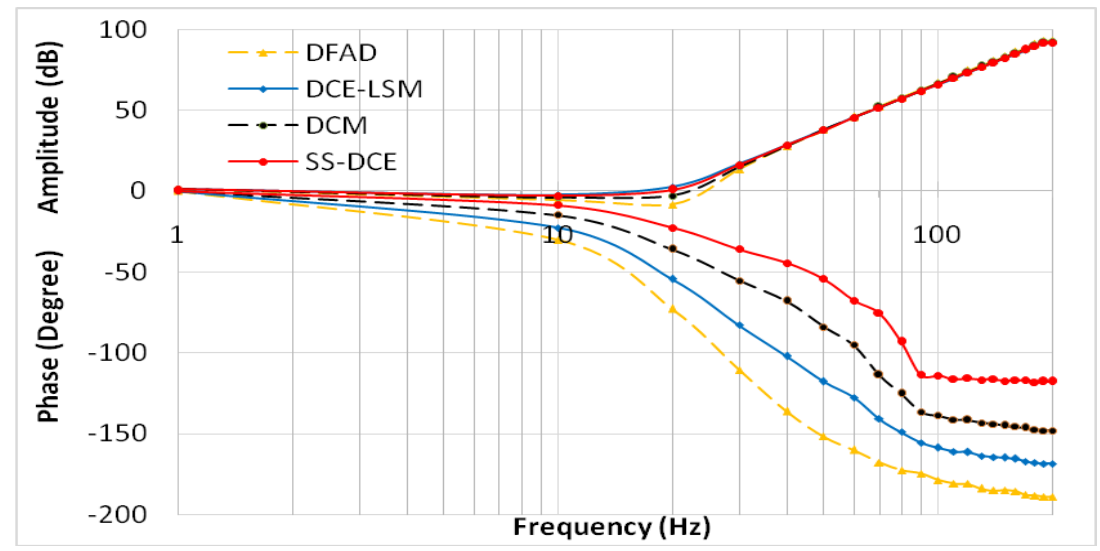

Figure 21. Gain and phase response of $G x(\omega)$.

Comparison of the simulation results of DFAD, DCM and DCE-LSM demonstrated that the estimation precision of DCE-LSM was higher than the output of the other estimators due to the sampling current accuracy and estimation algorithm. The difference between DCE-LSM and reference sensor was the smallest, and the linearity was the best. Meanwhile, the DFAD, DCM and SS-DCE estimation methods were affected by the signal data sampled once in the PWM switching cycle.

\subsection{Experimental Results}

To verify the estimator and restrict the air gap of the rotor in the 50-250 $\mu \mathrm{m}$ range, the output of the position estimator was compared to that of the eddy current sensor HZ-891. The linearity test results are shown in Figures 22-26. 


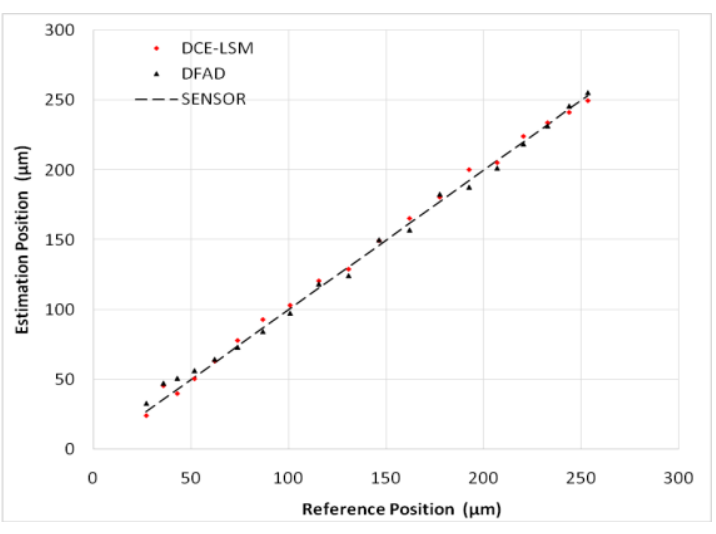

(a) Linearity of DCE-LSM and DFAD

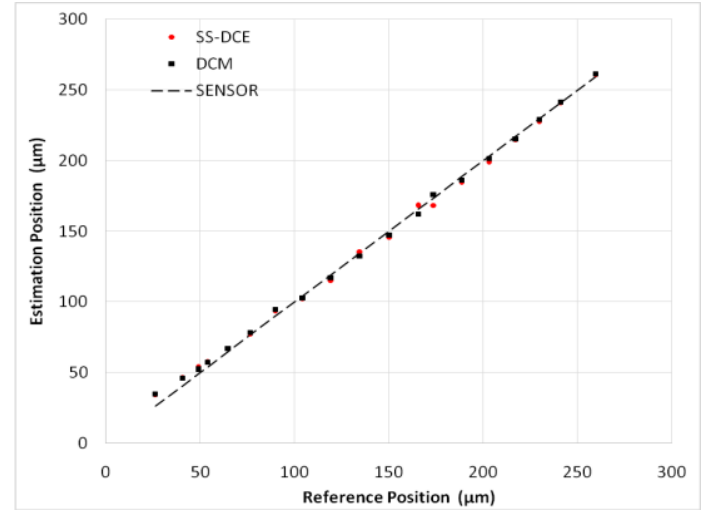

(b) Linearity of SS-DCE and DCM

Figure 22. Experimental result of estimator linearity $(20 \mathrm{~Hz})$.

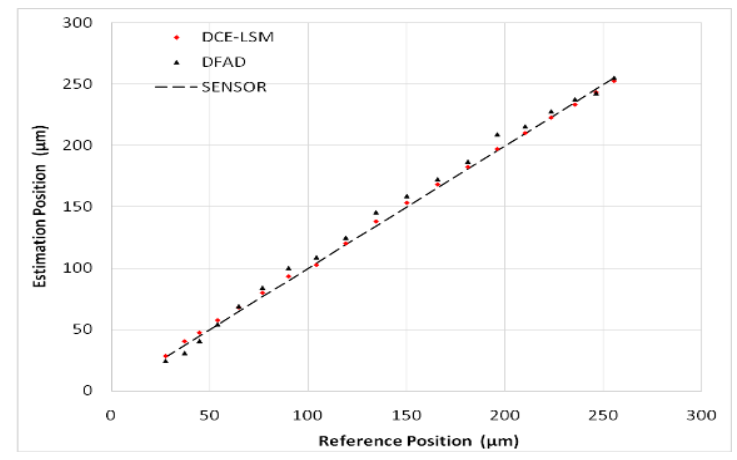

(a) Linearity of DCE-LSM and DFAD

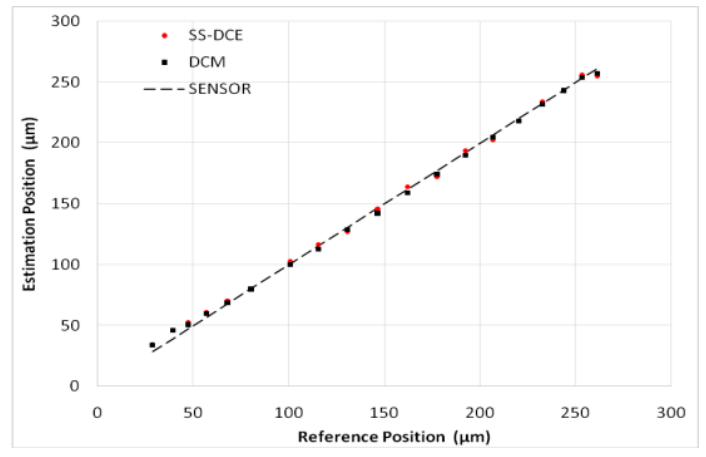

(b) Linearity of SS-DCE and DCM

Figure 23. Experimental result of estimator linearity $(50 \mathrm{~Hz})$.

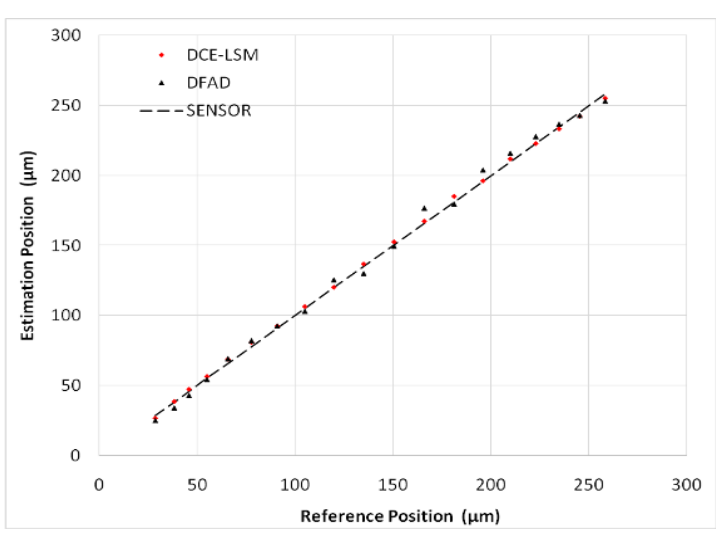

(a) Linearity of DCE-LSM and DFAD

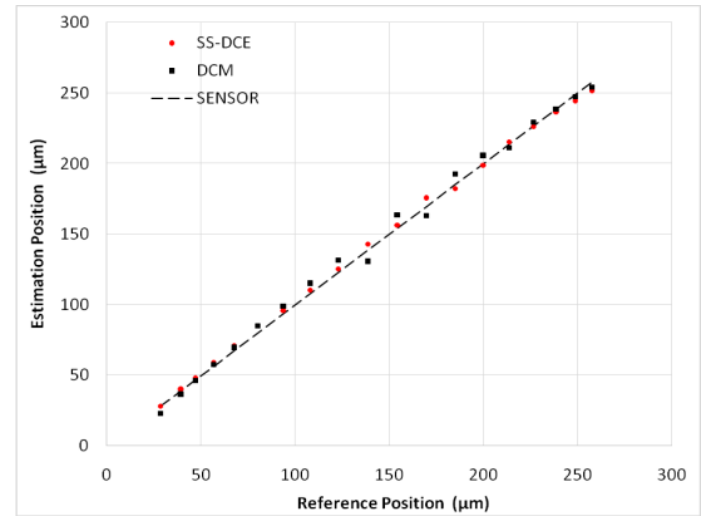

(b) Linearity of SS-DCE and DCM

Figure 24. Experimental result of estimator linearity $(100 \mathrm{~Hz})$. 


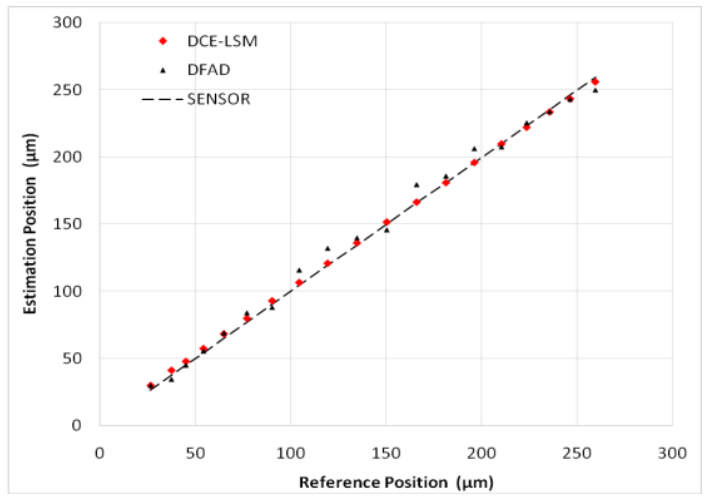

(a) Linearity of DCE-LSM and DFAD

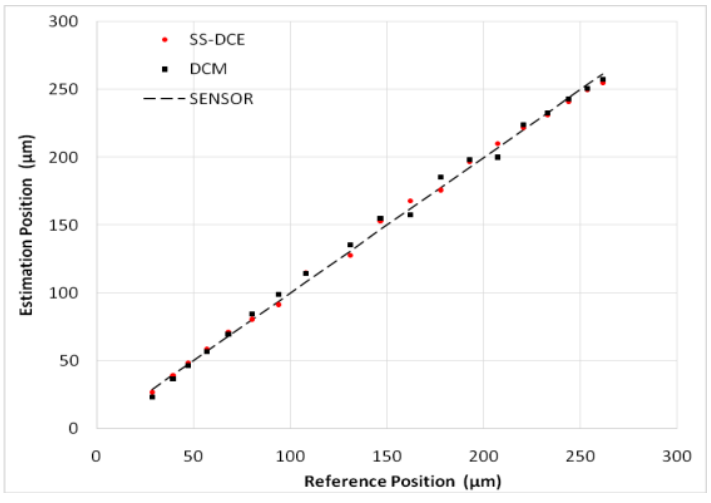

(b) Linearity of SS-DCE and DCM

Figure 25. Experimental result of estimator linearity $(150 \mathrm{~Hz})$.

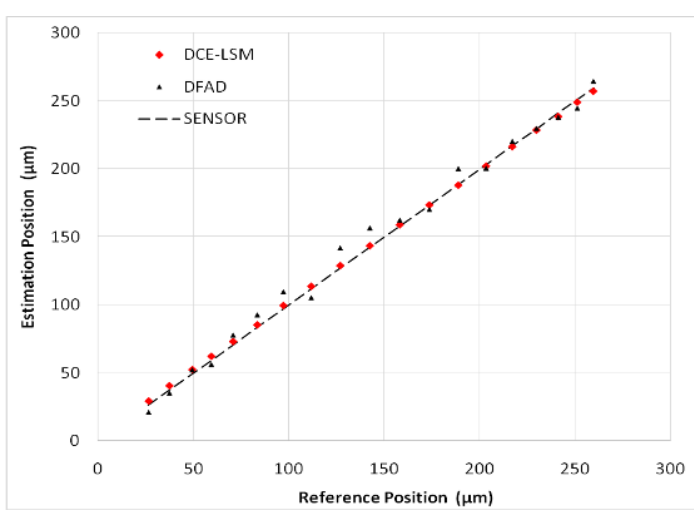

(a) Linearity of DCE-LSM and DFAD

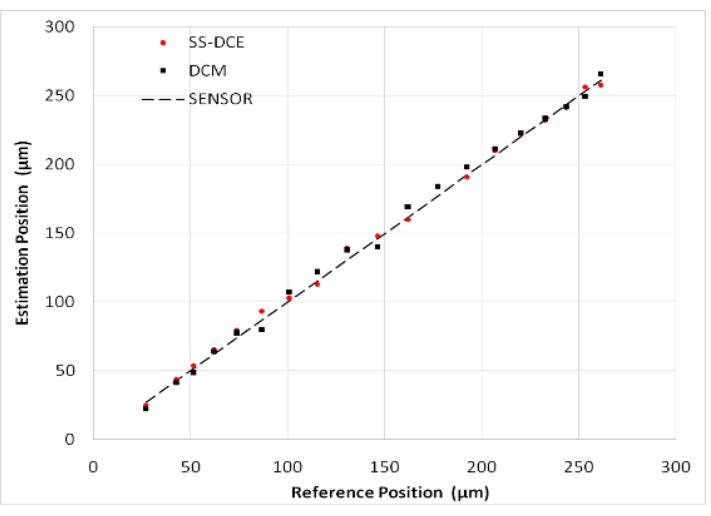

(b) Linearity of SS-DCE and DCM

Figure 26. Experimental result of estimator linearity $(200 \mathrm{~Hz})$.

The estimation linearity of DCE-LSM was better than that of the others, and its estimation precision was less than $2 \%$ when the test frequency was far from the natural frequency. Due to more additional phase-shifts introduced in the sensor process, the linearity of DFAD was the poorest; the estimation accuracy presented in Figure 27 is about $6 \%$. The precision of DCM and SS-DCE basically maintained a similar level. The experimental results are slightly better than the simulation results because the rotor was dominated by the damping force of the eddy current that included the motion and electrical eddy current. This damping force was also associated with and affected the rotor vibration and position estimator reported by Yu et al. [52] and Ji et al. [53]. Moreover, the experimental results of the four estimators regarding the mass are consistent with the simulation results.

The input sensitivity analysis was operated according to ISO-14,839-3 because no robustness indicators exist for self-sensing AMBs. In Figure 28, the suspended rotor was excited by a sinusoidal signal with a 10- $\mu$ m peak-peak value from 20 to $200 \mathrm{~Hz}$. The results demonstrate that the input sensitivity peak value listed in Table 4 occurred when the frequency $(20 \mathrm{~Hz})$ was close to the natural frequency; the AMBs with SS-DCE kept the lowest sensitivity.

Table 4. Summary of the input sensitivity of the proposed estimators.

\begin{tabular}{ccccc}
\hline Estimator & DFAD & DCE-LSM & DCM & SS-DCE \\
\hline Sensitivity Peak & 13.7 & 11.2 & 10.9 & 10.7 \\
\hline
\end{tabular}




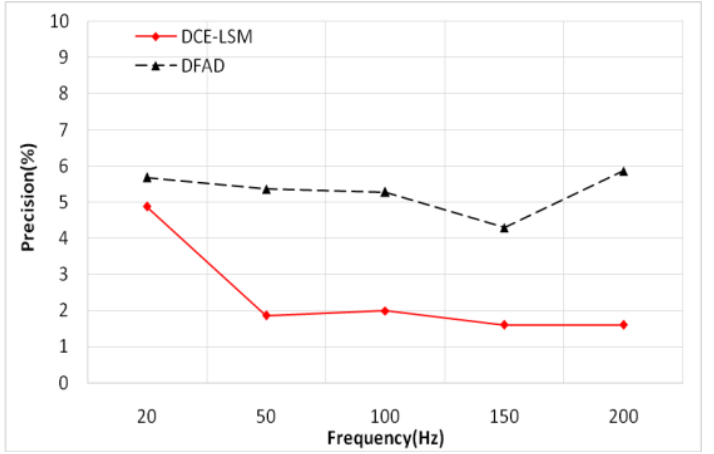

(a) Precision of DCE-LSM and DFAD

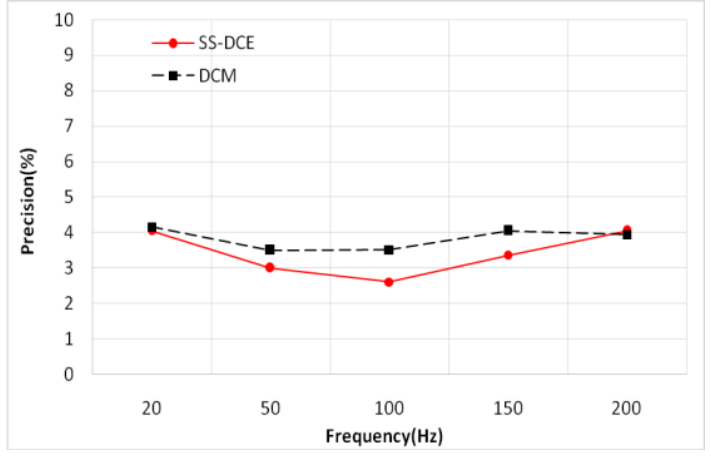

(b) Precision of SS-DCE and DCM

Figure 27. Experimental result of estimator precision.

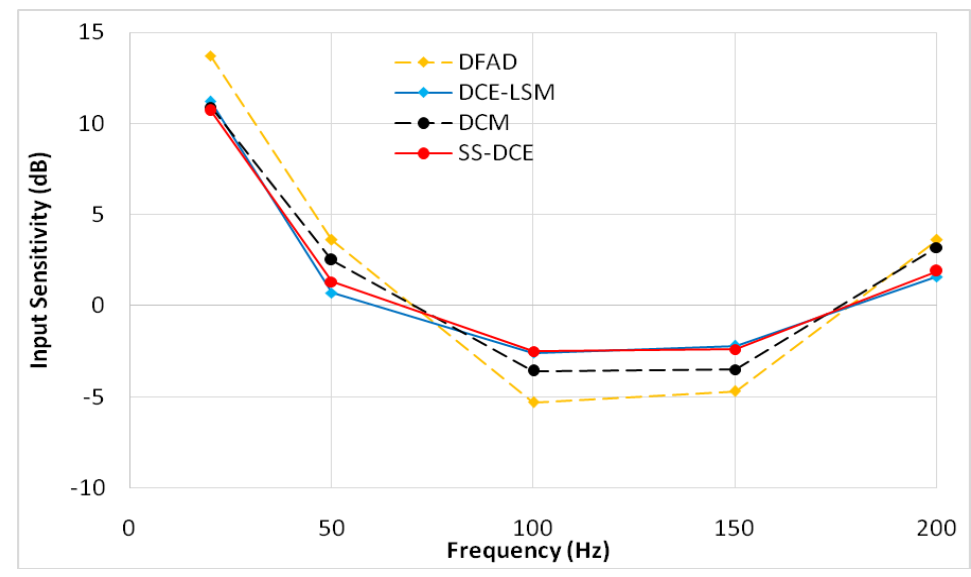

Figure 28. Experimental input sensitivity of estimators.

\section{Conclusions}

In this study, the phase shift and stability challenges introduced by demodulation filters and self-sensing algorithms were addressed with the proposed SS-DCE approach. The strengths and weaknesses of this approach were determined by comparison to four different position estimation approaches of AMBs.

A large number of filters are applied in the DFAD and DCM approaches to estimate the position obtained by the fundamental amplitude of the current and voltage. Due to the additional phase-shift introduced by these filters, the system bandwidth is limited, and the achievable stability margin is reduced. A novel method for the position estimation of self-sensing AMBs with a PWM-controlled magnetic suspension system was proposed based on a detailed mathematical model that is a viable description of the effect of switching PAs on the time evolution of the rotor current and position. Based on an analysis of the charging/discharging phases of the coil, the error induced by both a working value of the electric resistance and the dynamic inductance was considered.

Compared to these different methods, the SS-DCE approach had great advantages regarding its estimator. When the test frequency $(20 \mathrm{~Hz})$ was close to the natural frequency, the error and precision of all estimators achieved the best performance. When the test frequency was far from the natural frequency, the DCE-LSM estimation's linearity was better than that of the others; the simulation result was less than $2 \%$, and the corresponding experimental result was about $2 \%$ in the $50-250 \mu \mathrm{m}$ range. Due to more additional phase-shifts introduced in the sensor process, the linearity of DFAD was the poorest, and the estimation linearity presented was about $6 \%$. Similar linearity between SS-DCE and DCM was less than $4 \%$. However, SS-DCE had an excellent dynamics performance in the open-loop 
state, which was evaluated by a frequency response analysis; a $158^{\circ}$ phase margin was shown as at the natural frequency of $19.26 \mathrm{~Hz}$, and the sensitivity peak is $10.7 \mathrm{~dB}$ in the $50-250 \mu \mathrm{m}$ range.

According to the simulation and experimental results, the precision of the amplitude demodulation approach was lower because of the neglected dynamic estimation of inductance and the insufficient signal data in the estimation process. DCE-LSM considered the inductance dynamics and optimized the calculation algorithm, but its calculation overhead was too excessive, increasing the hardware and software costs. Thus, SS-DCE was derived, wherein an emphasis was placed on a special description of the influence of the switching amplifier on the duty cycle evolution of the current. Furthermore, the robustness limitations of self-sensing magnetic bearings are concerned in the commercial application. A limitation of this study is that it only applies to self-sensing AMBs using bistate switching PA.

Author Contributions: Conceptualization, X.H. F.X. R.W. and D.T.; methodology, X.H. and D.T.; software, X.H.; validation, X.H. F.X. and D.T.; formal analysis, X.H.; investigation, X.H. and D.T.; resources, X.H. and D.T.; data curation, X.H.; writing—original draft preparation, X.H. and D.T.; writing-review and editing, X.H. F.X. R.W. and D.T.; visualization, X.H.; supervision, F.X.; project administration, F.X. and D.T.; funding acquisition, F.X. and D.T. All authors have read and agreed to the published version of the manuscript.

Funding: This research was funded by the National Natural Science Foundation of China by means of Grant Number 51775501 and by the Zhejiang Provincial Natural Science Foundation of China under LR16E050001, and by National Key R\&D Program of China under 2018YFB1309404.

Acknowledgments: Thanks to Chengye Lang, Zhejiang University of technology, for providing the help in editing and grammar. The authors would like to thank the anonymous reviewers for their valuable comments.

Conflicts of Interest: The authors declare no conflicts of interest.

\section{References}

1. Vischer, D. Sensorless and Voltage Driven Magnetic Bearing [D]; Swiss Federal Institute of Technology: Lausanne, Switzerland; Zurich, Switzerland, 1988.

2. Cannon, R.H.; Rosenthal, D.E. Experiments in control of flexible structures with noncolocated sensors and actuators. J. Guid. 1984, 7, 546-553. [CrossRef]

3. Karkoub, M.; Balas, G.J.; Tamma, K. Colocated and noncolocated control design via $\mu$-synthesis for flexible manipulators. In Proceedings of the 1995 American Control Conference-ACC'95, Seattle, WA, USA, 21-23 June 1995; Volume 15, pp. 3321-3325. [CrossRef]

4. Malsen, E.H.; Schweitzer, G. Magnetic bearings: Theory, design, and application to rotating machinery. In Self-Sensing Magnetic Bearings; Maslen, E.H., Ed.; Springer: Dordrecht, The Netherlands; Heidelberg, Germany; London, UK; New York, NY, USA, 2009; pp. 329-338. ISBN 978-3-642-00497-1. [CrossRef]

5. Vischer, D.; Bleuler, H. Self-sensing active magnetic levitation. IEEE Trans. Magn. 1993, 29, $1276-1281$. [CrossRef]

6. Mizuno, T.; Bleuler, H.; Gähler, C.; Vischer, D. Towards practical applications of self-sensing magnetic bearings. In Proceedings of the 3rd International Symposium on Magnetic Bearings, Washington, DC, USA, 29-31 July 1992; pp. 169-175.

7. Morse, N.; Smith, R.; Paden, B.; Antaki, J. Position Sensed and Self-Sensing Magnetic Bearing Configurations and Associated Robustness Limitations. In Proceedings of the IEEE Conference on Decision and Control Including the Symposium on Adaptive Processes, Tampa, FL, USA, 18 December 1998; Volume 3, pp. 2599-2604. [CrossRef]

8. Maslen, E.H.; Montie, D.T.; Iwasaki, T. Robustness limitations and self-sensing magnetic bearings. J. Dyn. Syst. Meas. Control Trans. ASME 2006, 128, 197-203. [CrossRef]

9. Park, Y.H.; Han, D.C.; Park, I.H. A self-sensing technology of active magnetic bearings using a phase modulation algorithm based on a high frequency voltage injection method. J. Mech. Sci. Technol. 2008, 22, 1757-1764. [CrossRef]

10. Ge, Y.Q.; Wang, C.S.; Zhou, X.M.; Wang, H. Research on rotor position sensing of a permanent magnet synchronous motor based on high-frequency voltage injection and Kalman filter. In Proceedings of the 2010 International Conference on Electrical and Control Engineering (ICECE 2010), Wuhan, China, 25-27 June 2010; pp. 1750-1754. [CrossRef] 
11. Bugsch, M.; Piepenbreier, B. HF Test Current-Ripple-Control-Based Sensorless Method for SynRMs in the Low- and Zero-Speed Range Leading to an Adaptive Square-Wave-Shaped Voltage Injection. In Proceedings of the 2018 IEEE 9th International Symposium on Sensorless Control for Electrical Drives (SLED), Helsinki, Finland, 13-14 September 2018; pp. 24-29. [CrossRef]

12. Tan, D.P.; Ji, S.M.; Jin, M.S. Intelligent computer-aided instruction modeling and a method to optimize study strategies for parallel robot instruction. IEEE Trans. Educ. 2013, 56, 268-273. [CrossRef]

13. Okada, J.; Matsuda, K. Nagai, Sensorless magnetic levitation control by measuring the PWM carrier frequency component. In Proceedings of the 3rd International Symposium on Magnetic Bearings, Washington, DC, USA, 29-31 July 1992; pp. 176-183.

14. Noh, M.D. Self-Sensing Magnetic Bearings Driven by a Switching Power Amplifier. Ph.D. Thesis, University of Virginia, Charlottesville, WV, USA, 1996.

15. Mizuno, T.; Araki, K.; Bleuler, H. Stability analysis of self-sensing magnetic bearing controllers. IEEE Trans. Control Syst. Technol. 1996, 4, 572-579. [CrossRef]

16. Schammass, A.; Herzog, R.; Buhler, P.; Bleuler, H. New results for self-sensing active magnetic bearings using modulation approach. IEEE Trans. Control Syst. Technol. 2005, 13, 509-516. [CrossRef]

17. Lu, J.; Feng, K. Study on MSMA Self-Sensing Actuator Based on DSP. In Proceedings of the 2019 Chinese Automation Congress (CAC), Hangzhou, China, 22-24 November 2019; pp. 2866-2870. [CrossRef]

18. Zhang, Z.L.; Du, Z.M.; Deng, L.; Zhou, C.; Cao, Z.Q.; Cheng, L. A Fusion Measurement Method Based on Kalman Filter with Improved State Block and Neural Network for Nanometer Displacement. In Proceedings of the 2018 IEEE International Conference on Mechatronics and Automation (ICMA), Changchun, China, 5-8 August 2018; pp. 539-544. [CrossRef]

19. Zhang, L.; Yuan, Z.; Tan, D.; Huang, Y. An improved abrasive flow processing method for complex geometric surfaces of titanium alloy artificial joints. Appl. Sci. 2018, 28, 1037. [CrossRef]

20. Pan, Y.; Ji, S.M.; Tan, D.P. Cavitation based soft abrasive flow processing method. Int. J. Adv. Manuf. Technol. 2019. [CrossRef]

21. Tan, D.P.; Zhang, L.B.; Ai, Q.L. An embedded self-adapting network service framework for networked manufacturing system. J. Intell. Manuf. 2019, 30, 539-556. [CrossRef]

22. Tan, D.P.; Li, L.; Yin, Z.C.; Li, D.F.; Zhu, Y.L.; Zheng, S. Ekman boundary layer mass transfer mechanism of free sink vortex. Int. J. Heat Mass Trans. 2020, 150, 119250. [CrossRef]

23. Yu, J.; Zhu, C.S. Self-sensing active magnetic bearing using Hilbert transform. J. Zhejiang Univ. Eng. Sci. 2015, 49, 732-739. [CrossRef]

24. Li, L.; Qi, H.; Yin, Z.C.; Li, D.F.; Zhu, Z.L.; Tangwarodomnukun, V.; Tan, D.P. Investigation on the multiphase sink vortex Ekman pumping effects by CFD-DEM coupling method. Powder Technol. 2020, 360, 462-480. [CrossRef]

25. Li, C.; Ji, S.M.; Tan, D.P. Softness abrasive flow method oriented to tiny scale mold structural surface. Int. J. Adv. Manuf. Technol. 2012, 61, 975-987. [CrossRef]

26. Li, C.; Ji, S.M.; Tan, D.P. Multiple-loop digital control method for $400 \mathrm{~Hz}$ inverter system based on phase feedback. IEEE Trans. Power Electron. 2013, 28, 408-417. [CrossRef]

27. Haarnoja, T.; Halmeaho, T.; Manninen, A.; Tammi, K. Position estimation method for self-sensing electric machines based on the direct measurement of the current slope. In Proceedings of the 7th IET International Conference on Power Electronics, Machines and Drives (PEMD 2014), Manchester, UK, 8-10 April 2014; p. 16. [CrossRef]

28. Tian, Z.; Wei, Z.; Guo, B.; Sun, Y. A Rotor Displacement Estimation Method for Magnetic Bearings with Direct Measurement of the Ripple Current Slope. In Proceedings of the 2019 IEEE International Conference on Mechatronics and Automation (ICMA), Tianjin, China, 4-7 August 2019; pp. 1848-1853. [CrossRef]

29. Zhang, L.B.; Lv, H.P.; Tan, D.P.; Xu, F.; Chen, J.L.; Bao, G.J.; Cai, S.B. An adaptive quantum genetic algorithm for task sequence planning of complex assembly systems. Electron. Lett. 2018, 54, 870-871. [CrossRef]

30. Zhang, L.; Wang, J.S.; Tan, D.P.; Yuan, Z.M. Gas compensation-based abrasive flow processing method for complex titanium alloy surfaces. Int. J. Adv. Manuf. Technol. 2017, 92, 3385-3397. [CrossRef]

31. Glück, T.; Kemmetmüller, W.; Tump, C.; Kugi, A. A novel robust position estimator for self-sensing magnetic levitation systems based on least squares identification. Control Eng. Pract. 2011, 19, 146-157. [CrossRef]

32. Rizzello, G.; Naso, D.; York, A.; Seelecke, S. Self-sensing in dielectric electro-active polymer actuator using linear-in-parametes online estimation. In Proceedings of the 2015 IEEE International Conference on Mechatronics (ICM), Nagoya, Japan, 6-8 March 2015; pp. 300-306. [CrossRef] 
33. Rizzello, G.; Fugaro, F.; Naso, D.; Seelecke, S. Simultaneous Self-Sensing of Displacement and Force for Soft Dielectric Elastomer Actuators. IEEE Robot. Autom. Lett. 2018, 3, 1230-1236. [CrossRef]

34. Li, L.; Lu, J.F.; Fang, H.; Yin, Z.C.; Wang, T.; Wang, R.H.; Fan, X.H.; Zhao, L.J.; Tan, D.P.; Wan, Y.H. Lattice Boltzmann method for fluid-thermal systems: Status, hotspots, trends and outlook. IEEE Access 2020, 8, 27649-27675. [CrossRef]

35. Nevaranta, N.; Jaatinen, P.; Vujolainen, J.; Sillanpaa, T. Adaptive MIMO pole placement control for commissioning of a rotor system with active magnetic bearings. Mechatronics 2020, 65, 74-81. [CrossRef]

36. Sun, Y.; Shen, Q.; Ye, H. Speed-sensorless control system of bearingless induction motor based on modified adaptive fading unscented kalman filter. Trans. Chin. Soc. Agric. Eng. 2018, 34, 74-81. [CrossRef]

37. Yang, Z.; Wang, M.; Sun, X. Control system of bearingless induction motors based on adaptive neuro-fuzzy inference system. Trans. Chin. Soc. Agric. Eng. 2014, 30, 78-86. [CrossRef]

38. Ge, J.Q.; Tan, D.P.; Ji, S.M. A gas-liquid-solid three-phase abrasive flow processing method based on bubble collapsing. Int. J. Adv. Manuf. Technol. 2018, 95, 1069-1085. [CrossRef]

39. Sun, Z.; Zhao, J.J.; Shi, Z.G. Soft sensing of magnetic bearing system based on support vector regression and extended Kalman filter. Mechatronics 2014, 24, 186-197. [CrossRef]

40. Matsuda, K.; Kijimoto, S.; Kanemitsu, Y. Self-Sensing Three-Pole Magnetic Bearing Using a Kalman Filter. In Proceedings of the 2006 SICE-ICASE International Joint Conference, Busan, Korea, 18-21 October 2006; pp. 1590-1594. [CrossRef]

41. Ranft, E.O.; Van Schoor, G.; Du Rand, C.P. Self-sensing for electromagnetic actuators Part II: Position estimation. Sens. Actuator A Phys. 2011, 172, 410-419. [CrossRef]

42. Van Schoor, G.; Niemann, A.C.; Du Rand, C.P. Evaluation of demodulation algorithms for robust self-sensing active magnetic bearings. Sens. Actuator A Phys. 2013, 189, 441-450. [CrossRef]

43. Yu, J.; Zhu, C.S. A Multifrequency Disturbances Identification and Suppression Method for the Self-Sensing AMB Rotor System. IEEE Trans. Ind. Electron. 2018, 65, 6382-6392. [CrossRef]

44. Li, J.; Ji, S.M.; Tan, D.P. Improved soft abrasive flow finishing method based on turbulent kinetic energy enhancing. Chin. J. Mech. Eng. 2017, 30, 301-309. [CrossRef]

45. Hu, X.; Xu, F.; Tan, D. A synchronous sampling-based direct current estimation method for self-sensing active magnetic bearings. J. Zhejiang Univ. Sci. A 2020, 41, 401-405. [CrossRef]

46. Niemann, A.C.; Van Schoor, G.; Du Rand, C.P. A Self-sensing active magnetic bearing based on a direct current measurement approach. Sensors 2013, 13, 12149-12165. [CrossRef] [PubMed]

47. Yu, J.; Zhu, C.S. Position estimation accuracy improvement based on accurate modeling of self-sensing active magnetic bearings. Sens. Actuator A Phys. 2016, 248, 233-245. [CrossRef]

48. Ji, S.M.; Ge, J.Q.; Tan, D.P. Wall contact effects of particle-wall collision process in two-phase particle fluid. J. Zhejiang Univ. Sci. A 2017, 18, 958-973. [CrossRef]

49. Tan, D.P.; Chen, S.T.; Bao, G.J.; Zhang, L.B. An embedded lightweight GUI component library and the ergonomics optimization method for industry process monitoring. Front. Inform. Technol. Electron. Eng. 2018, 19, 604-625. [CrossRef]

50. Tang, M.; Zhu, C.; Yu, J. Cooperative rotor position estimation of active magnetic bearings with unsaturated magnetic bias. Trans. China Electrotech. Soc. 2014, 29, 205-212. [CrossRef]

51. Jiang, Y.; Wang, K.; Sun, M.; Xie, J. Displacement self-Sensing method for AMB-rotor systems using current ripple demodulations combined with PWM command signals. IEEE Sens. J. 2019, 19, 5460-5469. [CrossRef]

52. Yu, J.; Zhu, C.; Yu, Z. Rotor position estimation strategy for self-sensing active magnetic bearing considering eddy currents. Trans. China Electrotech. Soc. 2018, 33, 1946-1956. [CrossRef]

53. Ji, S.M.; Xiao, F.Q.; Tan, D.P. Analytical method for softness abrasive flow field based on discrete phase model. Sci. China Technol. Sci. 2010, 53, 2867-2877. [CrossRef]

54. Wang, Y.; Ni, P.; Wen, D.; Lin, Q.; Wang, D.; Ma, C.; Rao, Y.; Wang, H.; Tan, D. Dynamic performance optimization of circular sawing machine gearbox. Appl. Sci. 2019, 9, 4458. [CrossRef]

55. Cao, G.Z.; Pan, J.F.; Huang, S.D.; Qiu, H. Control Algorithms and Their Realization in the Magnetic Levitation System; Tsinghua University Press: Beijing, China, 2013; p. 80. ISBN 9787302308966.

(C) 2020 by the authors. Licensee MDPI, Basel, Switzerland. This article is an open access article distributed under the terms and conditions of the Creative Commons Attribution (CC BY) license (http://creativecommons.org/licenses/by/4.0/). 